\title{
Implications of groundwater behaviour on the geomechanics of rock slope stability
}

\author{
J Price SRK Consulting (Australasia) Pty Ltd, Australia
}

\begin{abstract}
Groundwater interaction is recognised as one of the key variables influencing slope design and management and is particularly significant in weaker rock masses. Understanding groundwater and pore pressure behaviour in rock masses is generally based on accepted theory related to flow through porous granular media. The presence of discontinuous geological structures within rock masses distorts the accepted hydraulic behaviour and the profile and aperture variability presents the designer with a complex challenge.

The paper adopts a geotechnical perspective and provides a review of our understanding of the interaction of groundwater with rock masses, including the accepted mechanics of water flow through granular and fractured media. The discussion considers how this behaviour can be expected to be locally modified and what implications this may have for slope stability. The discussion references observations as well as laboratory testing and physical measurements with consideration of the role of tortuous laminar flow and capillarity.
\end{abstract}

\section{Introduction}

The focus of this paper is on taking some of the theoretical and conceptualised geotechnical and hydrogeological aspects of soil and rock and relating them to actual geological conditions where non-linear anisotropic and discontinuous characteristics are commonly encountered. The discussion is especially focussed on the geotechnical considerations of water flow and pore pressure gradients.

The characteristics of the rock mass dictate whether:

- Interconnected discontinuities are present.

- The rock mass is massive, homogenous and isotropic.

- The rock mass is a combination of a relatively porous massive media with a superimposed fracture network.

The above-mentioned geomechanical environments require different conceptualisations to analyse flow. The former can be represented as impermeable discontinuous rock blocks bounded by a fracture network; the latter can be hydraulically represented as a combination of a porous continuum with a fracture network. The dual porosity concept is applicable where the rock block conductivity is of a similar order to that of the bounding fractures. As the rock matrix conductivity decreases relative to the fractures, a single porosity model attributed only to secondary permeability becomes increasingly applicable.

Rock slopes comprise a typically discontinuous mass of intersecting fractures and granular media. Porous media approaches ignore the effects of rock mass defects, and consider flow through intergranular void spaces, i.e. are mainly concerned with primary or effective primary permeability. Discontinuous media approaches apply known locations and defect dimensions (i.e. secondary permeability) to analyse fluid flow, and can include or neglect intergranular flow depending upon the relative magnitudes of each permeability component. Each approach represents the ends of a spectrum of geological conditions to which either model is applicable to a degree.

The geological complexity of pit slope environments complicates the evaluation of the conditions. In granular and fractured media, the relationship between flow rate and hydraulic gradient has been shown to be linear during laminar flow, in accordance with Darcy's law. However, with the increase of frictional losses from the 
onset of turbulent flow or flow separation from surface roughness and inertial effects occurring from aperture variation, non-linear flow laws, e.g. Missbach or Forcheimer need to be considered (Elsworth \& Doe 1986; Indraratna et al. 1994).

Gale (1990) demonstrated that accurate measurement of aperture, particularly residual aperture, is critical to the reasonable calculation of conductivity and fluid velocity. Despite demonstrating close agreement between computed and measured inflow rates, he identified that the mean fluid velocity contradicted tracer testing results, suggesting that at the local or small-scale, non-linear behaviour was present.

The following discussion explores some of the key aspects of the mechanical and hydraulic behaviour of rock masses, as well as providing some insight in to the challenges.

\section{$2 \quad$ Groundwater management in open pits}

The importance of effective management of water in open pit mining has become increasingly well recognised as pit slope designs have deepened below the groundwater table and maximum rates of vertical advance have been sought by mine planners, as documented by Stacey and Read (eds 2009) and Beale et al. (2014). Particular areas of careful evaluation are needed in (meta) sedimentary bulk commodities, e.g. iron and coal, or styles of mineralisation that have led to significant alteration of the rock mass especially in wet tropical environments, e.g. copper porphyries. The significant influences of groundwater in the geotechnical process are summarised in Tables 1 and 2 . The work flow and evolution over the life of the study clearly show the important interaction of groundwater in geotechnical design and management.

Table 1 The slope design process with significant groundwater influences (after Beale et al. 2014). Bold text highlights specific relevance to groundwater

\begin{tabular}{|c|c|c|}
\hline Slope design stage & Main component & Key elements and inputs \\
\hline \multirow[t]{3}{*}{ Model } & $\begin{array}{l}\text { Geotechnical model informed by } \\
\text { data collection }\end{array}$ & $\begin{array}{l}\text { Geology - substance and } \\
\text { structure }\end{array}$ \\
\hline & & Rock mass \\
\hline & & Hydrogeology \\
\hline \multirow[t]{3}{*}{ Domain } & Geotechnical domains & Geotechnical model \\
\hline & & Common geotechnical behaviour \\
\hline & & Potential failure modes \\
\hline \multirow[t]{4}{*}{ Design } & Slope geometry - bench, & Geotechnical domains \\
\hline & inter-ramp and overall slope & Regulatory regime \\
\hline & & Equipment specification \\
\hline & & Mine planning and schedule \\
\hline \multirow[t]{5}{*}{ Analyses } & Preliminary analysis — slope & Strength \\
\hline & geometry inputs & Structure \\
\hline & & Groundwater pressure \\
\hline & Final design - optimisation & In situ stress \\
\hline & & Risk assessment \\
\hline \multirow[t]{4}{*}{ Implementation } & Design implementation and & Blasting \\
\hline & refinement & Dewatering \\
\hline & & Depressurisation \\
\hline & & Slope monitoring \\
\hline
\end{tabular}


Table 2 Levels of effort by project stage - concept to feasibility (adapted from eds Stacey \& Read 2009 and Beale et al. 2014)

\begin{tabular}{|c|c|c|c|}
\hline $\begin{array}{l}\text { Project status } \\
\text { Stage }\end{array}$ & $\begin{array}{l}\text { Conceptual } \\
\text { Level } 1\end{array}$ & $\begin{array}{l}\text { Pre-feasibility } \\
\text { Level } 2\end{array}$ & $\begin{array}{l}\text { Feasibility } \\
\text { Level } 3\end{array}$ \\
\hline Geological model & $\begin{array}{l}\text { Regional literature; advanced } \\
\text { exploration mapping and core } \\
\text { logging; database established; } \\
\text { initial country rock model }\end{array}$ & $\begin{array}{l}\text { Mine scale outcrop and core } \\
\text { logging, enhancement of } \\
\text { geological database; initial } \\
\text { 3D geological model }\end{array}$ & $\begin{array}{l}\text { Infill drilling and mapping, } \\
\text { further enhancement of the } \\
\text { geological database and } \\
\text { 3D model }\end{array}$ \\
\hline $\begin{array}{l}\text { Structural model } \\
\text { (major features) }\end{array}$ & $\begin{array}{l}\text { Aerial photographs and initial } \\
\text { ground proofing }\end{array}$ & $\begin{array}{l}\text { Mine scale outcrop mapping; } \\
\text { targeted oriented drilling; } \\
\text { initial structural model }\end{array}$ & $\begin{array}{l}\text { Trench mapping; infill } \\
\text { oriented drilling; } \\
\text { 3D structural model }\end{array}$ \\
\hline $\begin{array}{l}\text { Structural model } \\
\text { (fabric) }\end{array}$ & Regional outcrop mapping & $\begin{array}{l}\text { Mine scale outcrop mapping; } \\
\text { targeted oriented drilling; } \\
\text { database established; initial } \\
\text { stereographic assessment of } \\
\text { fabric data; initial structural } \\
\text { domains established }\end{array}$ & $\begin{array}{l}\text { Infill trench mapping and } \\
\text { oriented drilling; } \\
\text { enhancement of the } \\
\text { database; advanced } \\
\text { stereographic assessment of } \\
\text { the fabric data; } \\
\text { confirmation of the } \\
\text { structural domains }\end{array}$ \\
\hline $\begin{array}{l}\text { Hydrogeological } \\
\text { model }\end{array}$ & Regional groundwater survey & $\begin{array}{l}\text { Mine scale airlift, pumping } \\
\text { and packer testing to } \\
\text { establish initial } \\
\text { hydrogeological parameters; } \\
\text { initial hydrogeological } \\
\text { database and model } \\
\text { established }\end{array}$ & $\begin{array}{l}\text { Targeted pumping and airlift } \\
\text { testing; piezometer } \\
\text { installation; enhancement } \\
\text { of the hydrogeological } \\
\text { database and 3D model; } \\
\text { initial assessment of } \\
\text { depressurisation and } \\
\text { dewatering requirements }\end{array}$ \\
\hline $\begin{array}{l}\text { Intact rock } \\
\text { strength }\end{array}$ & $\begin{array}{l}\text { Literature values } \\
\text { supplemented by index tests } \\
\text { on core from geological } \\
\text { drilling }\end{array}$ & $\begin{array}{l}\text { Index and laboratory testing } \\
\text { on samples selected from } \\
\text { targeted mine scale drilling } \\
\text { database established; initial } \\
\text { assessment of lithological } \\
\text { domains }\end{array}$ & $\begin{array}{l}\text { Targeted drilling and } \\
\text { detailed sampling and } \\
\text { laboratory testing; } \\
\text { enhancement of database; } \\
\text { detailed assessment of the } \\
\text { establishment of } \\
\text { geotechnical units for } \\
\text { 3D geotechnical model }\end{array}$ \\
\hline $\begin{array}{l}\text { Strength of } \\
\text { defects }\end{array}$ & $\begin{array}{l}\text { Literature values } \\
\text { supplemented by index tests } \\
\text { on core from geological } \\
\text { drilling }\end{array}$ & $\begin{array}{l}\text { Laboratory direct shear } \\
\text { strength from targeted mine } \\
\text { scale drillholes and outcrops; } \\
\text { database established; } \\
\text { assessment of defect strength } \\
\text { with initial structural domains }\end{array}$ & $\begin{array}{l}\text { Targeted sampling and } \\
\text { laboratory testing; } \\
\text { enhancement of database; } \\
\text { detailed assessment and } \\
\text { establishment of defect } \\
\text { strengths within structural } \\
\text { domains }\end{array}$ \\
\hline $\begin{array}{c}\text { Geotechnical } \\
\text { characterisation }\end{array}$ & $\begin{array}{l}\text { Pertinent regional } \\
\text { information; geotechnical } \\
\text { assessment of advanced } \\
\text { exploration data }\end{array}$ & $\begin{array}{l}\text { Assessment and compilation } \\
\text { of initial mine scale } \\
\text { geotechnical data; } \\
\text { preparation of initial } \\
\text { geotechnical database and } \\
\text { 3D model }\end{array}$ & $\begin{array}{l}\text { Ongoing assessment and } \\
\text { compilation of new mine } \\
\text { scale geotechnical data; } \\
\text { enhancement of } \\
\text { geotechnical database and } \\
\text { 3D model }\end{array}$ \\
\hline
\end{tabular}

The importance of groundwater in slope management frequently requires that analysis and decision-making are made by multi-disciplinary teams, which dictates that a common understanding of the rock mass behaviour from each party is needed, which takes account of frequently different approaches to data 
collection and analysis but which can present opportunities for short and long-term cost saving when conducted to take advantage of the synergies. Tables 1 and 2 demonstrate the recommended work process, as well as the level of development that is suggested to be established during the study phase of the project (and sustained through detailed design and operations). The residual risk in the slope design reflects the understanding of the mining environment and level of effort committed to the study. Engagement with stakeholders and the acceptability of the risk profile is a key element to communicating the intended performance of the slope design.

\section{Critical mechanical behaviour}

Critical aspects of mechanical behaviour include the following.

\subsection{Coupling and effective stress}

The theory of hydromechanical coupling in soil and rock is well addressed by authors, represented by Sullivan (2007) and include Neuzil (2003), and Rutqvist and Stephansson (2003). The phenomena recognises the influence of change in boundary conditions, which result in changes in the physical conditions or properties. Four different coupling modes have been proposed by Wang (2000), and Rutqvist and Stephansson (2003), in Table 3.

Table 3 Hydromechanical coupling for soil and rock slopes (Sullivan 2007)

\begin{tabular}{ccc}
\hline Coupling mode & Type & Description \\
\hline 1 & Direct & Solid to fluid: a change in mechanical stress results in a change in fluid \\
pressure
\end{tabular}

In geotechnical engineering, especially pit slope stability, we most often consider incremental, large-scale deformation that is irrecoverable and results in changes in the material properties that are mostly part of the Type 3 and 4 coupling modes.

The theory of effective stress (Equation (1)), (Terzaghi 1923) is the fundamental step in understanding the engineering behaviour of soil and rock masses.

$$
\sigma^{\prime}=\sigma_{n}-u
$$

Effective stress $\left(\sigma^{\prime}\right)$ is equivalent to the total normal stress $\left(\sigma_{n}\right)$ at a point minus the pore pressure $(u)$, with $\sigma$ and $u$ a function of the relevant density and applied load. Weaker materials, such as most soils and some weathered or altered rocks, are generally most influenced by large pore pressures.

\subsection{Strength and material constitutive model}

For geotechnical materials, strength is often presented using the Mohr-Coulomb failure law, which can be written in terms of effective stress for a point along a failure surface, where $\tau$ is the shear strength at the point of interest, $\phi$ is the angle of internal friction and $c$ the cohesion.

$$
\tau=\left(\sigma_{n}-u\right) \tan \phi+c
$$

The strength parameters can be considered in either drained or undrained conditions, dependent upon the mode of failure being considered: drained strength parameters are considered where pore pressure 
dissipation is considered possible; undrained parameters are considered, for example, in soils where rapid loading occurs, which prevents the chance for pore fluid to drain away from the point of application.

The applicable constitutive model when considering material behaviour is decided based upon the expected post failure response. For weaker materials, the post failure strength changes and the rate of deformation is usually greater so that steady state or strain softening behaviour is most likely (Sullivan 1993).

\subsection{Compressibility}

\subsubsection{Matrix stiffness}

The change in volume of the soil or rock matrix can be considered in terms of elastic and plastic behaviour. Consolidation theory is particularly applicable to soils, and includes stages of initial elastic followed by inelastic behaviour (consolidation, settlement and creep). In rocks, geological processes have often led to lithification following exposure to extremes of pressure and temperature creating a corresponding reduction in the primary porosity and, therefore, the ability to transmit fluid. The presence of joints and other geological structures has the tendency to form higher, secondary porosity pathways that can provide alternate albeit anisotropic transmission pathways.

Deformation of normally consolidated soils or weaker materials is usually modelled in stages of elastic settlement, consolidation and creep. Consolidation considers the change in volume by the dissipation of excess pore pressure gradients by flow in granular media, by relating the coefficient of consolidation $\left(c_{V}\right)$ to the specific storage $\left(S_{S}\right)$ and hydraulic conductivity $(K)$, or the transmissivity $(T)$ and the storage coefficient $(S)$.

$$
c_{v}=\frac{K}{S_{S}}=\frac{T}{S}
$$

Transmissivity can be defined as $K$ multiplied by the aquifer thickness $b$. The storage coefficient is the product of $S_{S}$ and $b$, and the specific storage represents the water released per unit volume per unit drop in head.

$$
S_{S}=\rho g(\alpha+n \beta)
$$

where: $n$ is defined as the porosity, $\rho$ is the density of water, $g$ is the acceleration due to gravity, with the compressibility of the rock mass and water defined by $\alpha$ and $\beta$, respectively.

The influence of previous loading processes, including lithification, creates an over-consolidation that leads to materials appearing stiffer than would otherwise be expected from younger deposits. This influence needs to be considered, especially with weak rocks, when considering foundation and pore pressure dissipation.

\subsubsection{Fracture stiffness}

Fracture stiffness parameters are crucial for controlling the coupled stress:flow behaviour of a fracture and is often significantly less than the matrix. Several authors have studied the relationship between stress and conductivity, including Carlsson et al. (1990) and Indraratna et al. (1999a, 1999b).

Carlsson et al. (1990) tested sandstone and coal samples and found that there is a marked reduction of conductivity for rocks with a lower initial permeability value. Carlsson et al. (1990) did not compare rock type unconfined compressive strength or Young's modulus with initial conductivity or conductivity rate of change. The elastic properties of the different rock types have a fundamental impact on the rate of change of conductivity. Aperture closure was directly related to the elastic properties of the rock substance and the fractures. Brace (1980) considered fracture orientation and concluded that fractures parallel to the maximum principal stress would tend to dilate, whereas perpendicular fractures tended to close as loads increased.

Fracture deformation occurs from shear or normal deformation of the fracture walls. Shear test results reported by Makurat et al. (1990) indicated that conductivity increases of up to two orders of magnitude could occur, but as deformation increased, conductivity should decrease because of the formation of gouge material blocking the flow paths. Beyond an upper threshold normal stress, the aperture does not reduce 
any further, i.e. after achieving the residual aperture (Indraratna et al. 1999a; Cook et al. 1990). Residual aperture depends on initial aperture, as well as rock type and roughness profile.

Fracture deformation behaviour is related to aperture through elastic theory using their normal and shear stiffness $\left(K_{n}, K_{s}\right)$, as explained by Brady and Brown (1994) and presented in Equations (5) and (6). The contact force (normal or shear) is related to the corresponding displacement by a linear relationship:

$$
\begin{aligned}
F_{n} & =K_{n} \delta_{n} \\
F_{s} & =K_{s} \delta_{s}
\end{aligned}
$$

where: $F$ represents the force, $\delta$ is the displacement, and the subscripts $s$ or $n$ represent shear or normal orientations.

Chen et al. (1989) considered idealised fractures when assessing the impact of contact area on flow behaviour. They studied flow through an element of propped parallel plate using a boundary element with a smooth parallel plate model including several irregular contact areas of known area. They compared computed results with those recorded in laboratory experiments, as well as the predicted impact using the Walsh-Maxwell approach. If the contact area was included with irregular asperities, as would be expected for naturally rough surfaces, then the Walsh-Maxwell approach under-predicted the fracture flow by as much as $30 \%$. The equivalent aspect ratio of the contact area had to be included to make the analytical results agree with laboratory testing. This makes the correlation of joint behaviour with flow much more difficult in situ than in the laboratory.

The mechanical change in fracture (normal) aperture can be related to normal fracture stiffness $(K n)$ and change in applied normal stress $\left(\Delta \sigma_{n}\right)$. This should be written in terms of effective stress since the mechanical reaction of a water filled fracture will be mitigated by the fluid mixture with a pore pressure $p$, particularly where $p \approx \sigma_{n}$ (Equation (7)):

$$
\delta_{n}=\frac{\Delta \sigma_{n^{\prime}}}{K_{n}}=\frac{\Delta \sigma_{n-p}}{K_{n}}
$$

\section{$4 \quad$ Typical hydraulic factors influencing behaviour}

\subsection{Permeability}

Rock mass conductivity often appears in discussions on groundwater flow and is of fundamental importance in rock mechanics problems (Equation (8)). Intrinsic permeability $(k)$ defines the resistance to flow under a hydraulic gradient. The permeability is more correctly known as the 'intrinsic permeability' and is independent of the properties of the fluid, having units of $\left(\mathrm{m}^{2}\right)$. Hydraulic conductivity $(K)$ relates the intrinsic permeability to fluid dynamic viscosity $(\mu)$ and is a function of both permeant properties, i.e. water, and pore geometry:

$$
K=\frac{k g \rho_{f}}{\mu}=\frac{k g}{v}
$$

Water flow occurs in rocks through a combination of intergranular pores, fissures and interconnected fractures. Conductivity is recognised to often be represented by a range of values often spread across several orders of magnitude (Table 4). Rock mass conductivity $\left(K_{m}\right)$ is, therefore, the sum of the matrix or primary conductivity $(K)$ and the fracture or secondary conductivity $\left(K_{f}\right)$, Equation (9). Both flow mechanisms occur in most rocks but it is commonly accepted that due to the low primary porosity of many rocks, fracture flow is often the dominant mechanism:

$$
K_{m}=K+K_{f}
$$

Primary permeability is directly related to the material porosity, which varies depending upon factors such as rock type, geological history, and in situ stress conditions. Porosity can vary between $<1 \%$ for shales and 
granites to up to $50 \%$ for some clays and sandstones. Secondary permeability is a function of the fracture aperture geometry and connectivity.

Table 4 Typical values of primary and secondary hydraulic conductivity from laboratory and field tests (after Isherwood 1979)

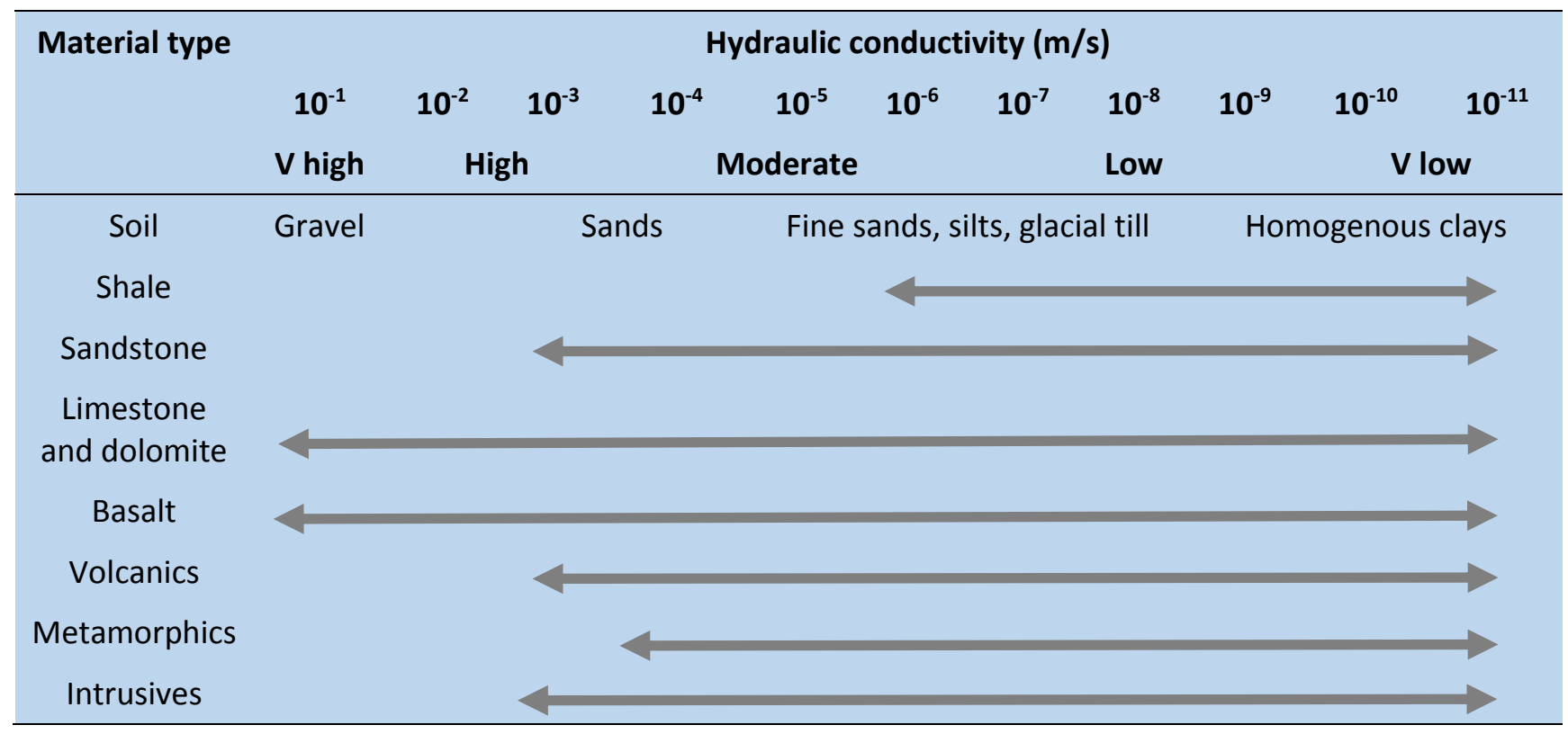

A variation in hydraulic conductivity for different rock types, of several orders of magnitude, is common. This variation is a function of the size of the sample in relation to the scale of the variability of the rock. Consideration of Equation (6) indicates, that in cases where the primary permeability is about two orders of magnitude less than the secondary permeability, the primary permeability is insignificant for most practical engineering purposes.

The head driving water flow is calculated from Bernoulli's equation. In seepage problems where the seepage velocity is slow, the effect of kinematic head can often be ignored (i.e. assumed that $V^{2} / 2 g \approx 0$ ). Thus, total head is defined as the sum of pressure head and elevation head above a datum (Equation (10)):

$$
h=\frac{u_{p}}{\gamma_{f}}+z
$$

where: $h$ is total head $(\mathrm{m}), u_{p}=$ pore pressure $(\mathrm{kPa}), \gamma_{f}=$ unit weight of fluid $\left(\mathrm{kN} / \mathrm{m}^{3}\right)$ and $z$ is elevation above datum $(m)$.

\subsection{Intergranular flow}

Under conditions commonly encountered in engineering projects intergranular, laminar flow of water can be analysed using Darcy's law (Equation (11)):

$$
Q=K A \frac{\Delta h}{L}
$$

where: $Q=$ flow rate $\left(\mathrm{m}^{3} \mathrm{~s}^{-1}\right), K=$ hydraulic conductivity $\left(\mathrm{ms}^{-1}\right), A=$ cross-sectional area of flow $\left(\mathrm{m}^{2}\right)$ and $\Delta h=$ change in head measured over a horizontal distance $L$.

Darcy's law should be recognised as a fundamental tool for the analysis of steady state, laminar flow, although it should be remembered that it provides an average or equivalent seepage linear velocity or flow rate since it does not consider the actual percolation path length. As such, the estimated values can be scale-dependent and accommodate local non-linear characteristics. 


\subsection{Fracture flow}

Lee and Farmer (1993) describe the evolution of fracture flow study and the application of Darcy's law from initial work by Romm (cited in Zeigler 1976) and Lomize (1951). The former used two parallel glass plates with apertures as small as $0.2 \mathrm{~mm}$, with Romm (cited in Zeigler 1976) concluding the formula was applicable to apertures as fine as $0.2 \mu \mathrm{m}$. The law is unsuitable for tight rough defects and for rough defects under high normal stress (Lee et al. 1993; Witherspoon et al. 1980). Lomize (1951) used marble and quartzite samples to demonstrate the cubic law validity for open fractures at low stresses, but with a departure at small apertures. Brown (1987) observed that the accuracy of cubic law predictions diminished when fracture surfaces became close, with flows about $50 \%$ of that predicted by cubic law theory. Louis (1968) and Brown (1987) found the Reynolds equation applicable in calculating flow, a fact confirmed theoretically by Zimmerman and Bodvarsson (1996). Iwai (1976) and Witherspoon et al. (1980) considered the law valid for natural rough uneven and open discontinuities as narrow as $4 \mu \mathrm{m}$. Witherspoon even developed Darcy's law to include a term related to the fracture aperture discussed. It is clear that fracture surface roughness can significantly affect the linearity of flow but, nonetheless, laminar and viscous flow is often approximated to flow between smooth parallel plates. In such cases, the conductivity of a single fracture is given by the cubic law (Equation (12)):

$$
K_{f}=\frac{g e^{3}}{12 v b}
$$

where: $K_{f}=$ fracture conductivity $\left(\mathrm{ms}^{-1}\right), e=$ hydraulic aperture $(\mathrm{m}), g=$ acceleration due to gravity $\left(\mathrm{ms}^{-2}\right)$, $v=$ kinematic viscosity $\left(\mathrm{m}^{2} \mathrm{~s}^{-1}\right),\left(1.01 \times 10^{-6}\right.$ for pure water at $\left.20^{\circ} \mathrm{C}\right)$ and $b$ is the spacing between fractures $(\mathrm{m})$. Equation (9) can then be re-written for an idealised case where regular spaced fractures intersect a rock mass. If the representative fracture aperture has a mean spacing that is $b$ then Equation (13) can be proposed.

$$
K_{m}=K+\frac{e}{b} K_{f}
$$

The calculation of an equivalent rock mass conductivity representing the effect of primary and secondary porosity is a crucial but complex problem. The use of the cubic law is valid for most engineering calculations except where fractures are significantly rough or pressure gradients are large (Figure 1). In these circumstances laminar flow behaviour can be replaced by transitional or turbulent flows. Early investigations applied concepts of pipe hydraulics to fracture flow applying the pressure drop coefficient and the Reynolds number (Louis 1968).

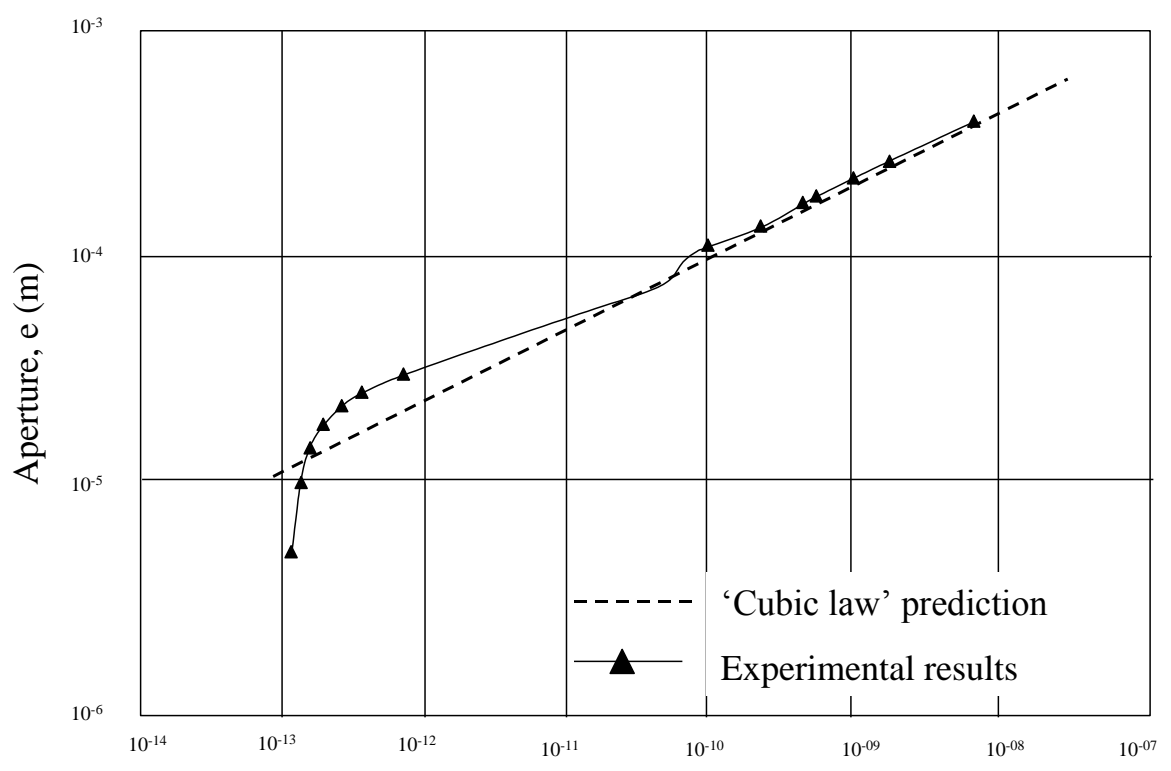

Flow rate per unit pressure gradient $\left(\mathrm{m}^{4} / \mathrm{Pa} \mathrm{s}\right)$

Figure 1 Sample plot showing the range of validity of the cubic law as presented by Long (1996) after work by Cook et al. (1990) 
The classical assumptions explain the expected behaviour under idealised conditions and at a particular scale, but frequently we have to consider the situation where local departures from expected behaviour need to be understood and incorporated into our designs, e.g. joint set characteristics, unsaturated flow and capillary effects.

\section{Small-scale characteristics}

For hydrogeological interpretation over the medium or large-scale, it should be remembered that there remains the potential for variability and departures from the typical hydraulic assumptions. An understanding of these characteristics helps to understand behaviour that could otherwise be considered as anomalous. The intersection of structures and their potential to conduct water is complicated by the variability in aperture. The capacity of a fracture to carry significant volumes of water means, nonetheless, that the characteristics need to be carefully considered from a perspective of project risk.

\subsection{Persistence and spacing}

The spatial representation of rock fabric can be measured after the fact using accepted manual or digital techniques. This data can be analysed statistically and used to provide inputs for the generation of synthetic fracture models. Prior to excavation, the sampling methods available to practitioners do not allow objective characterisation of joint properties, except at the small-scale.

It has been shown joint persistence can be modelled statistically using different distributions e.g. negative exponential or log-normal (Priest \& Hudson 1981). The shape of the fracture is also unknown but often approximated to a circle or at least an ellipse. The true spacing between joints within a set can also typically be modelled using a negative exponential for log-normal distribution. Joint intensity is the number of joints per unit length or volume.

\subsection{Aperture}

Indraratna et al. (1999b), and Zimmerman and Bodvarsson (1996), stress the role of aperture variation in flow behaviour, where, in reality, the aperture is rarely uniform, contrary to an assumption of the parallel plate law. They have shown it is possible to account for variation in mechanical aperture by using the lognormal mean hydraulic aperture in calculations based upon parallel plate theory. This is in keeping with the definitions described by Tsang (1984) in relation to the cubic law and in testing by Price (2005), (Figure 2).
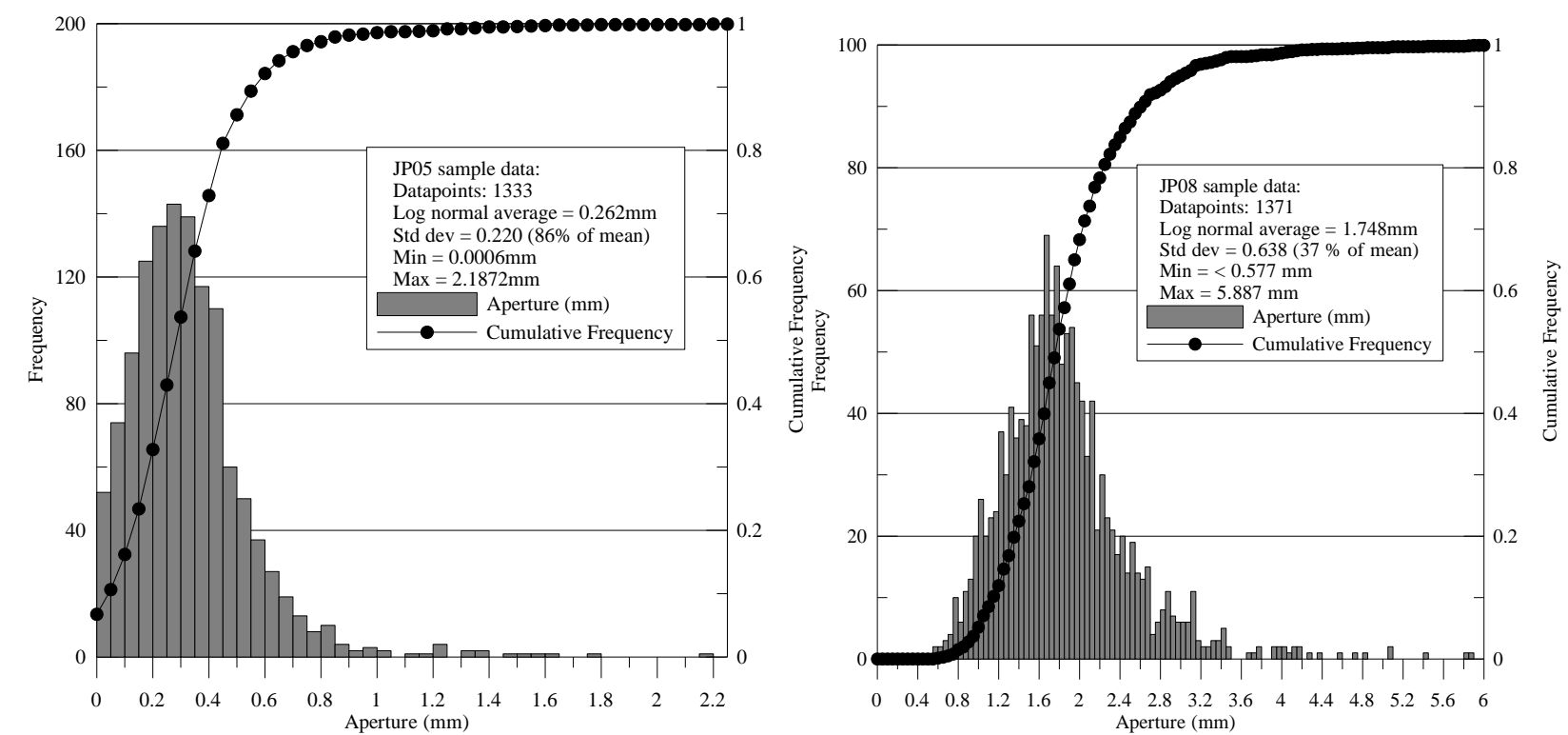

Figure 2 Aperture scan summaries for rock fractures in terms of aperture frequency and cumulative frequency 
Variable aperture models have been developed by Neuzil and Tracy (1981) and Tsang (1984), among others, which consider flow through small consecutive parallel plate elements. In these cases the element apertures are related by an aperture function. Where changes in aperture from element to element are small, Zimmerman and Bodvarsson (1996) indicate that the cubic law generally provides an acceptable solution. Detailed aperture topology provides a means of checking the validity of this approach.

Aperture distributions have been predicted from several laboratory studies and mathematical models, and aperture distribution is well predicted if a log-normal distribution is used (Hakami \& Barton 1990; Zimmerman \& Bodvarsson 1996). More recently, aperture and surface characterisation were conducted by the author (Price 2005) using a computer controlled laser scanner. Instrument optimisation enabled scans to be automatically recorded at $0.1 \mathrm{~mm}$ intervals in the $x-y$ plane, i.e. parallel to the fracture plane, to a vertical (z plane) precision of $\sim 0.008 \mathrm{~mm}$.

\section{$5.3 \quad$ Roughness}

\subsubsection{Measurement}

In geomechanics, roughness is referenced to standard $100 \mathrm{~mm}$ long profiles (ISRM 1978) by the joint roughness coefficient (JRC). In this study, rock samples were selected to be $100 \mathrm{~mm}$ long so that the scale effect did not complicate the interpretation. Longer wavelength roughness (relative to fracture length) impacts upon water flow (Barton et al. 1985). Fracture roughness tends to have a corresponding smaller impact on less viscous fluids, e.g. air (Di Biagio 1973).

Measurements of surface roughness can capture the variation in asperity amplitude and can be used to estimate the JRC of a profile (Figure 3), (Indraratna et al. 2002b; Price 2005). The variable nature of roughness means that roughness is not a unique value but can be defined by a single or multi-modal range, which has the controlling influence on behaviour. The direction of measurement and the potential for anisotropy need to be considered in case there is a connection to geotechnical performance, e.g. shear strength.
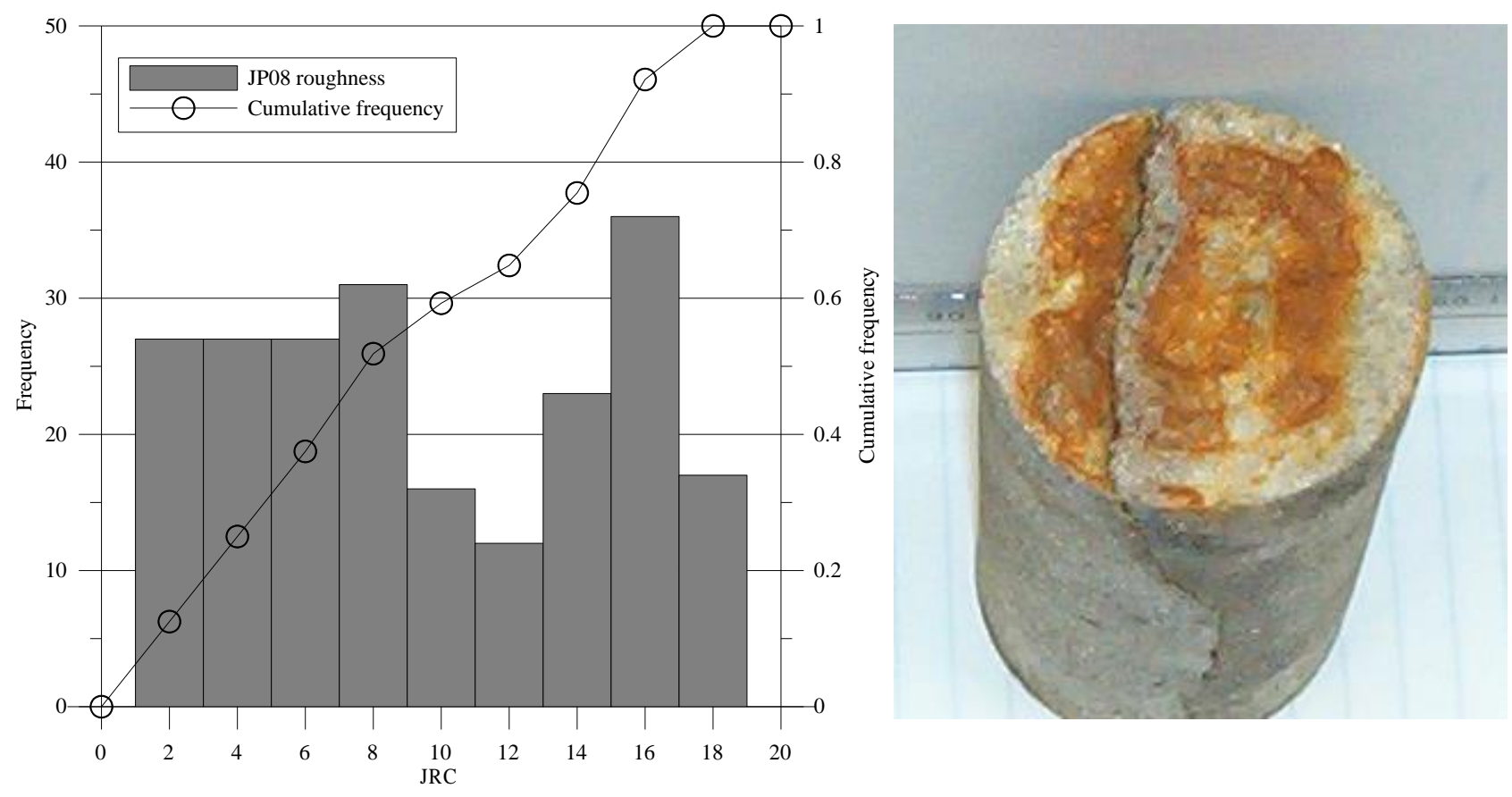

Figure 3 Illustration of joint roughness coefficient (JRC) assessment for a fracture surface measured with 10 equally spaced profiles of varying individual roughness

As an example, a comparison of the scanning data for different profiles and using different roughness evaluation methods can often indicate a range of interpreted average JRC values of 9 to 12 (Table 5). 
Table 5 Comparison of joint roughness coefficient (JRC) estimation methods

\begin{tabular}{cc|}
\hline Method & JRC average \\
\hline Regression - Milne & 12 \\
\hline Chord Angle - Seidel and Haberfield & 9 \\
\hline Fourier fit - Price & 9 \\
\hline Barton - simplified & 11 \\
\hline
\end{tabular}

This conclusion should not be a surprise if actual fracture topology is considered (Figure 4). Furthermore, in surfaces of varying roughness amplitude will generate an elemental distribution of variable fracture aperture at a particular scale, contrary to the simplified assumption of fracture smoothness, as illustrated by the upper plot of Figure 4.

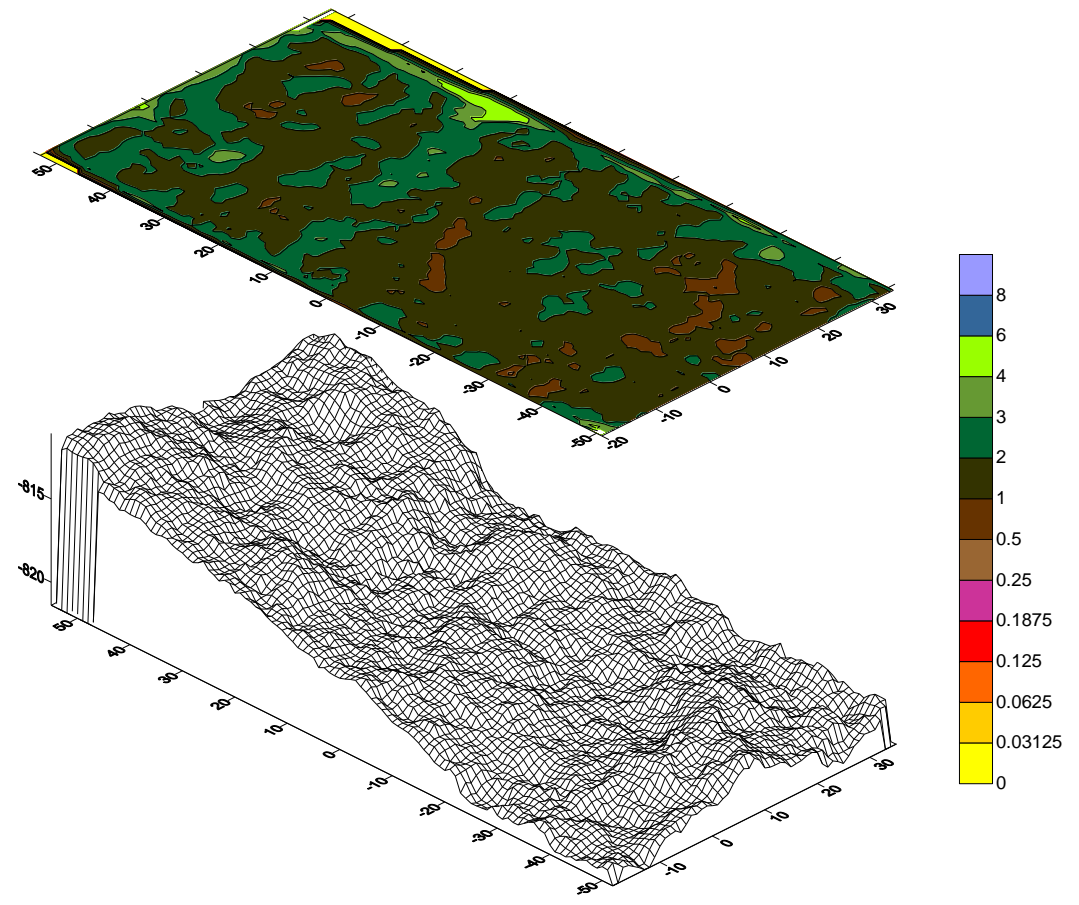

Figure 4 Sample JP08 wireframe and aperture contour plot

\subsubsection{Strength}

The literature review indicates that waviness, i.e. large-scale roughness, can be predominantly attributed to dilation and the observed increase in shear strength above the laboratory residual friction angle. Attempts have been made to define the large-scale wavelength, e.g. equal to at least $2 \%$ of the observed failure surface (McMahon 1985), to assist in measuring the expected shear strength.

The shear strength of a surface is related to the applied normal stress, the friction angle of the material and the roughness angle, as originally suggested by Patton (1966) in Equation (14) where shear is purely frictional:

$$
\tau=\sigma_{n} \tan \left(\phi_{u l t}+i\right)
$$

where: $i=$ roughness angle, i.e. the angle between mean dip angle of the discontinuity and the flattest dipping section of the required wavelength, $\sigma_{n}=$ normal stress acting on the discontinuity, and $\phi_{u l t}=$ ultimate or residual friction angle. Using the empirical approach from Barton and Choubey (1977), shear strength can be estimated using the estimated JRC and the joint wall compressive strength (JCS):

$$
\tau=\sigma_{n} \tan \left[J R C \log \left(\frac{J C S}{\sigma_{n}}\right)+\phi_{r}\right]
$$


The Barton and Choubey (1977) relationship shows for clean strong joints, the potential for an increase in available shear resistance under low confining stresses, as well as a greater shear strength for surfaces with a higher JRC. For infilled joints, the relevance of roughness depends on the thickness and the infill strength.

\subsubsection{Linear flow}

It has already been mentioned how the cubic law can lose validity at large pressure gradients or over very rough surfaces, i.e. non laminar flow, or where fractures are particularly tight, capillarity. In two-dimensional (2D), increases in roughness reduce the assumption of plate parallelism. In the third-dimension, this results in further increases flow path tortuosity in the fracture plane. Laboratory experiments (Witherspoon et al. 1980; Cook et al. 1990) showed that the back-calculated hydraulic aperture is less than the actual mechanical aperture under saturated conditions along a rough surface or in small aperture fractures. This discrepancy increases with increasing roughness under laminar flow conditions. Barton et al. (1985) developed an empirical relationship (Equation (16)) relating the hydraulic aperture $e_{h}$, mechanical aperture $e$ and the JRC for the condition $e_{m} / e_{h}$, apertures are measured in $\mu \mathrm{m}$ :

$$
e_{h}=\frac{e_{m}^{2}}{J R C^{2.5}}
$$

This equation is based upon laboratory data and accounts empirically for non-parallel flow across a rough surface. The relationship of JRC to fracture roughness, as described by the standard profiles proposed by ISRM (1978), provides a useful link to hydraulic and geotechnical behaviour. The hydraulic impact of roughness on flow can be considered using the Poiseuille's and Darcy's laws as described in Equation (17):

$$
Q=\frac{e_{h}^{3} w}{12 \mu}\left(\frac{d h}{d x}\right)
$$

Fracture roughness promotes frictional losses and reduces the flow rate of groundwater seepage. By combining the parallel plate equation for intrinsic permeability and the Barton et al. (1985) expression, the following equation can be developed in terms of mechanical aperture and JRC:

$$
k=\frac{e_{m}^{2}}{12 J R C^{5}}
$$

As illustrated in Figure 5, surface roughness increasingly impacts upon the continuity and thickness of the fluid boundary layer at the fracture wall, leading to increased flow path tortuosity and the development of localised turbulence. This behaviour causes the discrepancy between the actual or 'mechanical' aperture of a fracture and the hydraulic aperture that would be back-calculated from Poiseuille's law, when the hydraulic gradient and the flow rate are known. This characteristic is demonstrated by the relationship between hydraulic aperture $\left(e_{h}\right)$, mechanical aperture $\left(e_{m}\right)$ and JRC as proposed by Barton et al. (1985). The relationship in Equation (18) is empirical and aperture measurements are in microns and is valid for $e_{h} \leq e_{m}$. In practice, smooth fracture JRC, i.e. low roughness, can often be approximated by $e_{h}=e_{m}$. 


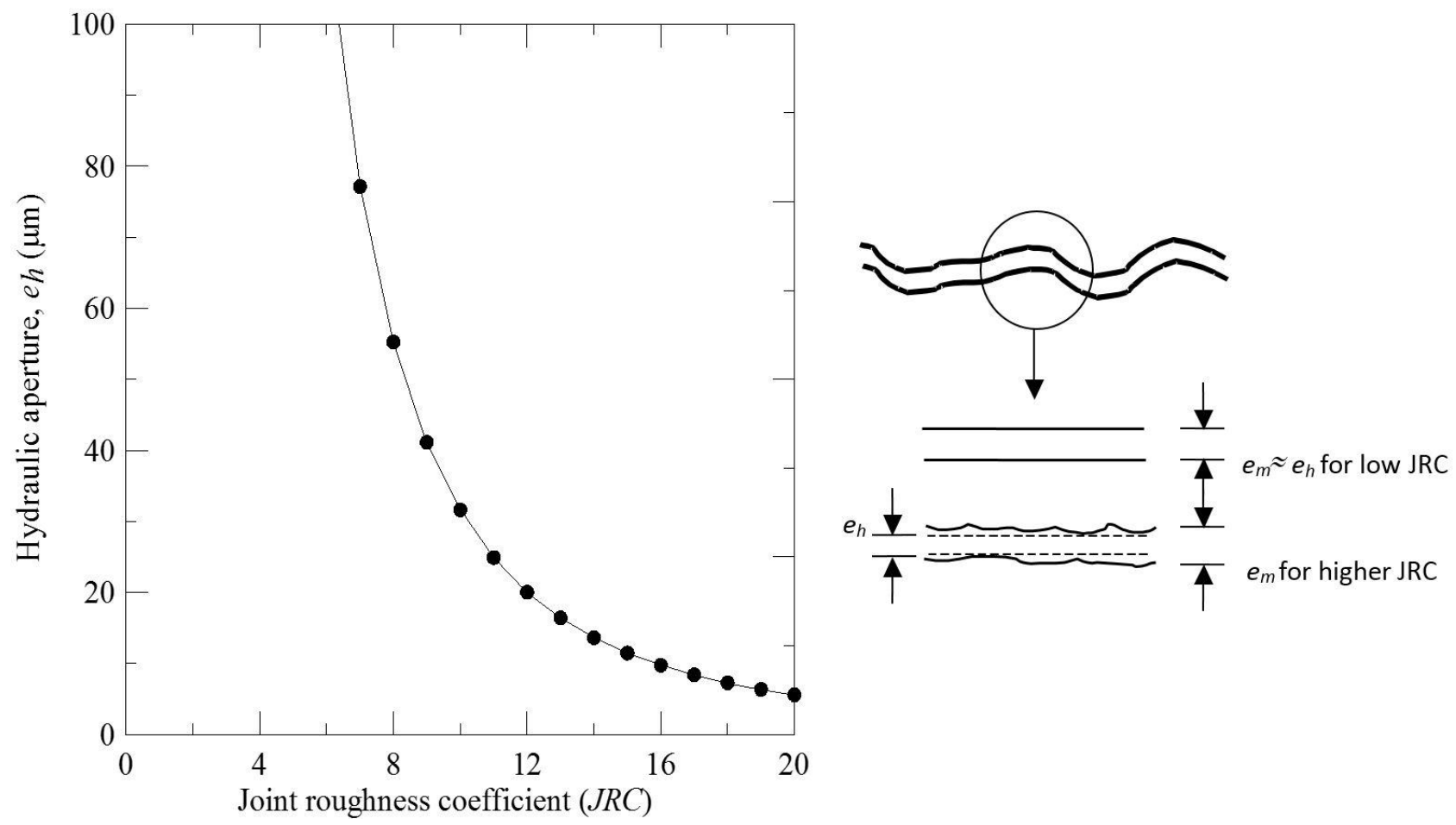

Figure 5 Relationship between hydraulic aperture $\left(e_{h}\right)$ and joint roughness coefficient for hypothetical fracture with mechanical aperture $\left(e_{m}\right)$ of $100 \mu \mathrm{m}$

Figure 6 also illustrates the effect of increased roughness by the reduction in intrinsic permeability $(k)$. The permeability (parallel plate model) calculated using the mechanical aperture $\left(e_{m}\right)$ for the condition $e_{m}=e_{h}$ is compared with the permeability calculated using the corresponding $e_{h}$ from Equation (18). The graph shows roughness impacts more severely on $k$ for small aperture defects by more than four orders of magnitude.

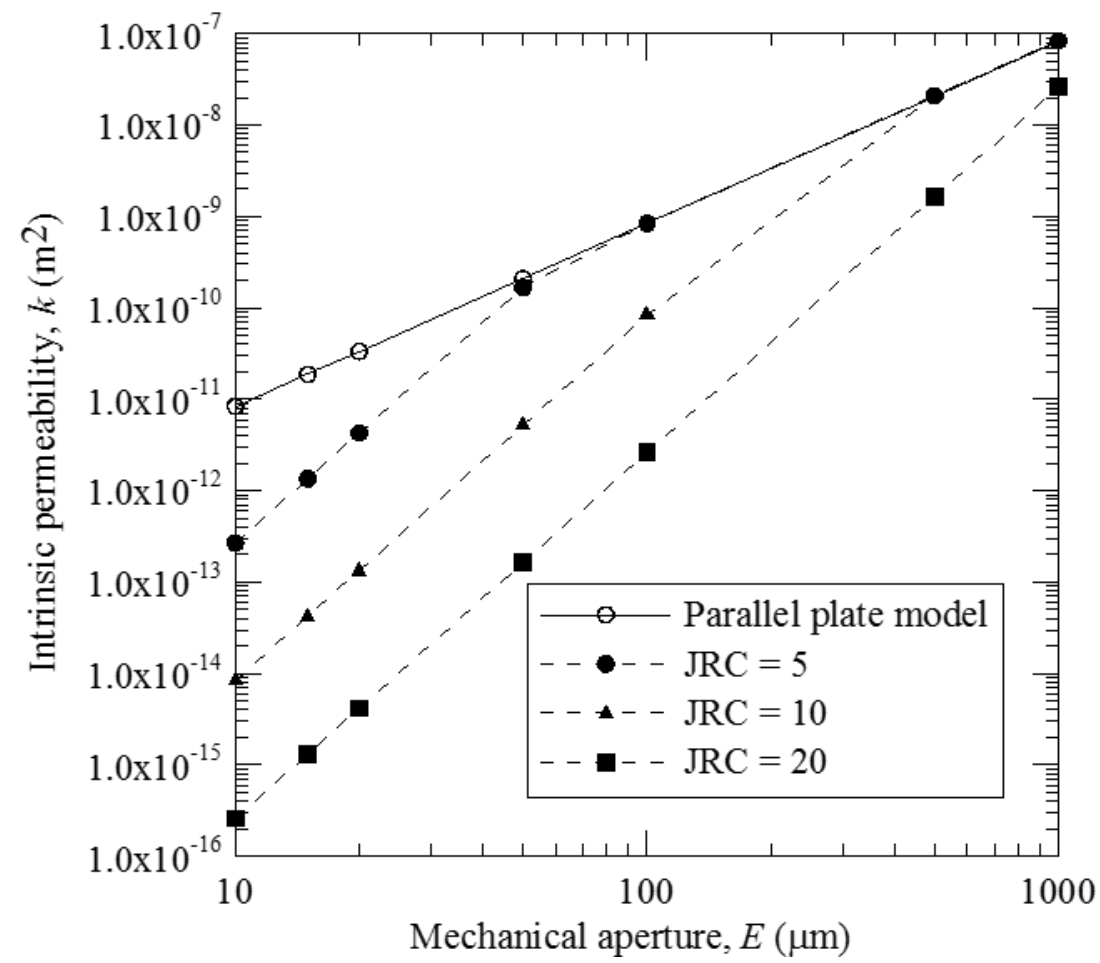

Figure 6 Graph showing relationship between mechanical aperture $\left(e_{m}\right)$ and intrinsic permeability ( $k$ ) for different fracture roughness (JRC) 


\subsubsection{Scalability}

The scalability of fracture roughness is recognised and correlations have been developed to the $100 \mathrm{~mm}$ reference length. Scale was studied by Barton \& Bandis (1980) leading to an expression (Equation (19)), which related the original $100 \mathrm{~mm} J R C_{0}$ profile to that of a profile length $L$.

$$
\frac{J R C_{L}}{J R C_{0}}=\left(\frac{L}{L_{0}}\right)^{0.02 J R C_{0}}
$$

The relationship shows that the effective roughness of a surface reduces as the profile length increases, until the surface is effectively smooth once the joint exceeds $25 \mathrm{~m}$. This relationship occurs because, as profile length extends, it is the larger scale waviness that has a predominant effect on the dilatant behaviour of the material, often coupled with an increase in the normal stress applied to the surface. The mechanical significance of this is that higher persistence structures can be identified discretely within analyses. Hydraulically this means, however, that the hydraulic aperture needs to be carefully considered at the scale at which measurement was made. The smallest pore or pore throat along a flow path will continue to control the flow that can be achieved and would not be altered despite the relative roughness decreasing to $J R C_{L}$.

\subsection{Non-linear flow}

The fracture hydraulic response to changes in pressure gradient has been well documented (Louis 1969; Elsworth \& Doe 1986; Lee \& Farmer 1993). The test shows a clear reduction in calculated aperture or flow with increased pressure gradient, as well as increasing confining stress.

The expected laminar to turbulent flow behaviour can be clearly demonstrated in test results (Price 2005). The single-phase tests record linear and non-linear flow conditions (Figures 7 and 8). For a specific confining stress, back-calculation of fracture aperture using these results shows a near constant aperture occurring over the range of linear flow conditions that decreases with the onset of turbulence. When the maximum aperture is plotted for a suite of tests over a range of confining stresses, a gradual reduction in the back-calculated aperture is observed.

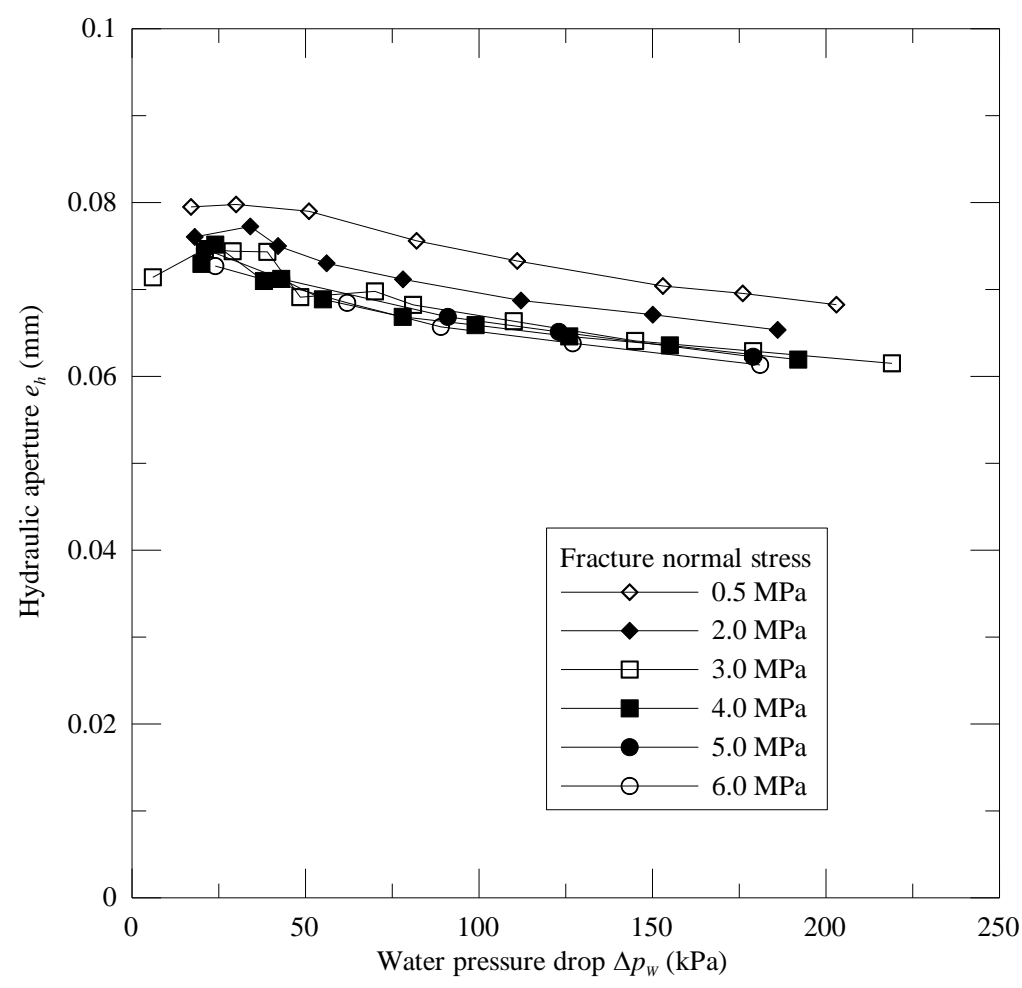

Figure 7 Single-phase flow test results over a range of confining conditions showing a plot of (back-calculated) hydraulic aperture and water phase pressure drop (Price 2005) 


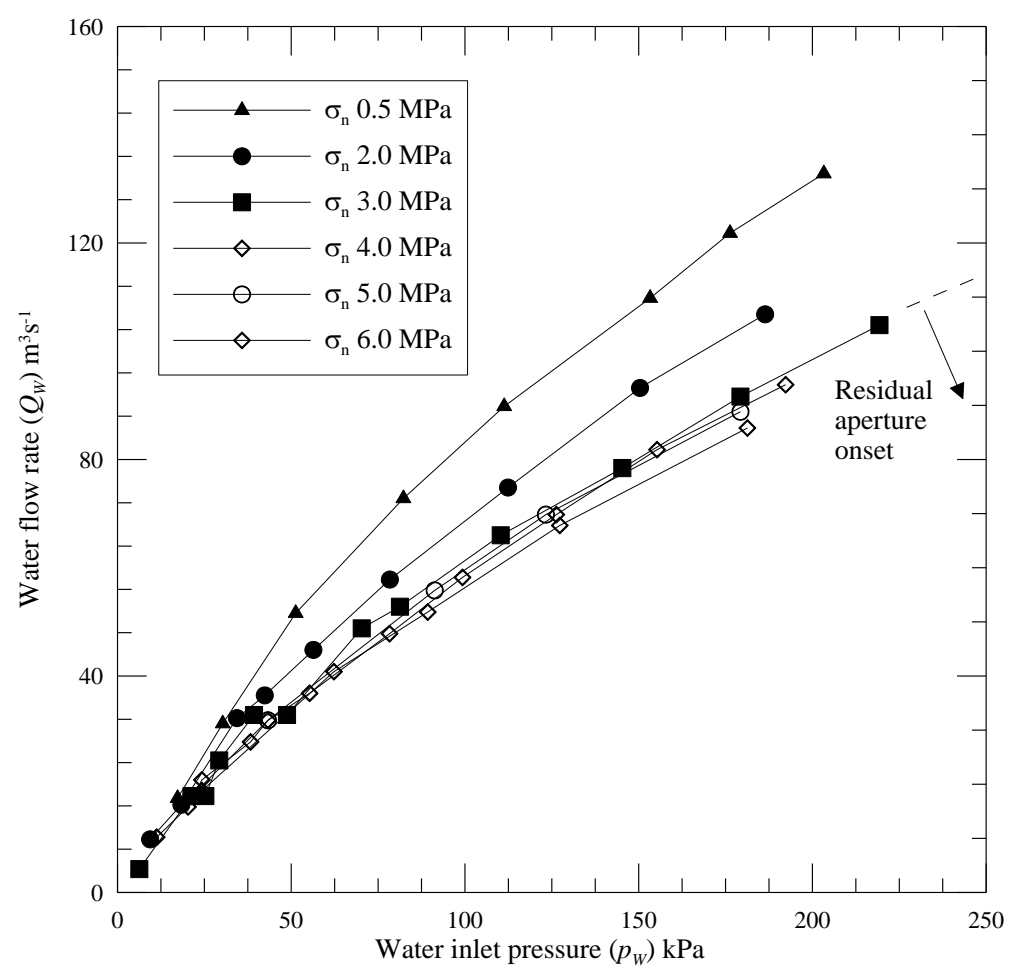

Figure 8 Impact of fracture normal stress and pressure drop on single-phase flow behaviour for test sample. Note the onset of residual aperture when normal stress exceeds 3 to $4 \mathrm{MPa}$

This study of fracture normal stress versus flow behaviour confirms established characteristics (Indraratna \& Ranjith 1999b; Price 2005). A plot of flow rate versus confining water inlet pressure (Figure 8 ) shows a gradual reduction in flow as fracture normal stress, i.e. confining stress, increases. With increased stress, the proportion of fracture contact area between the surfaces rises until the residual aperture is attained. This is signalled by a near non-reducible flow rate, as shown in Figure 8, beyond a confining stress of 3 to $4 \mathrm{MPa}$.

When flow conditions are not linear, an alternative law is needed to perform engineering analyses. There are two particular approaches to calculate the flow behaviour under these conditions. The transition between linear and fully non-linear flow is well described by the Forcheimer's law (Indraratna et al. 1994), (Equation (20)):

$$
\nabla \phi=a_{F} U+b_{F} U^{2}
$$

where: $\nabla \phi$ is the hydraulic gradient, $U$ is the average velocity and $a_{F}$ and $b_{F}$ are linear and non-linear constants. The Missbach equation (Equation (21)) is an alternative mathematical relationship for non-linear flow that has been more widely used in the analysis of pumping test data (Elsworth \& Doe 1986; Louis \& Maini 1972):

$$
U=-K \nabla \phi^{n}
$$

where: $K$ is hydraulic conductivity and $n$ is 0.5 for turbulent and 1 for laminar flow.

\subsection{Capillarity}

In unsaturated, low-flow or low pressure environments, where capillary flow is the dominant mechanism, water percolates between the fracture surfaces, driven in the form of dendritic fingers by the interaction of gravitational and capillary pressures (Nichol \& Glass 1994). Water percolates between fracture surfaces, driven in fingers by gravity, surface tension and capillary pressures, where capillary flow dominates. This mechanism is different to the laminar viscous flow concept discussed earlier. Capillarity is increasingly significant for smaller aperture fractures, given the established inverse relationship shown in Equation (22). 
Capillary pressure $\left(p_{c}\right)$ results in a curved 'interface' related to surface tension $\left(T_{s}\right)$ and the meniscus curvature at the air-water interface, following Pruess \& Tsang (1990).

$$
p_{C}=\left(T_{S} \cos \theta\right)\left(\frac{1}{r_{1}}-\frac{1}{r_{2}}\right)
$$

Assuming conservatively that the water is pure and temperature constant, surface tension remains unchanged $\left(72.75 \mathrm{mN} / \mathrm{m}\right.$ at $\left.20^{\circ} \mathrm{C}\right)$, (Fredlund $\&$ Rahardjo 1993). The terms $r_{1}$ and $r_{2}$ are the radii of curvature of the meniscus, measured perpendicular and parallel to the fracture plane, respectively. Assuming the contact angle $\theta$ to be zero, $r_{1}=e / 2$ and $r_{2}$ is very large, the above equation is simplified further:

$$
p_{C}=\left(2 T_{S}\right) / e
$$

Equation (23) shows that capillary pressure is increasingly important for narrow fractures, especially where pressures drops are relatively small. The capillary pressure defines the entry pressure above which imbibition of a phase can occur in an unsaturated medium. If three fluid phases are present, the lower $T_{S}$ value determines the displacement preference in a situation where phase pressure gradients are increasing. The potential for influence of capillarity on flow through voids and fractures is illustrated in Table 6.

Table 6 Comparison of threshold capillary pressure controlling void access

\begin{tabular}{cccc}
\hline Material & $\begin{array}{c}\text { Mechanical } \\
\text { aperture }(\boldsymbol{\mu m})\end{array}$ & $\begin{array}{c}\text { Particle size } \\
(\mathbf{m m})\end{array}$ & $\begin{array}{c}\text { Capillary access } \\
\text { pressure }(\mathrm{kPa})\end{array}$ \\
\hline Fracture & 0.01 & & 14,550 \\
& 0.1 & & 1,455 \\
& 1 & & 146 \\
& 10 & & 15 \\
\hline Clay & 100 & $<0.002$ & 2 \\
\hline Silt & 1,000 & 0.02 & 73 \\
\hline Fine sand & & 0.2 & 1 \\
\hline Coarse sand & & 2 & $<1$ \\
\hline Gravel & & $>2$ & $<1$ \\
\hline
\end{tabular}

The results demonstrate some interesting outcomes (Table 6): they confirm that capillary effects are more significant for fine grained and particularly clayey soils; for a sub-micron opening, pore accessibility requires a pressure drop of more than $15 \mathrm{~m}$ head.

It is interesting to remember that, particularly for intergranular flow, the pore throat is the smallest opening through which fluid is required to pass and will, dependent upon grain packing, be much less than the size of the particle resulting in high capillary pressures that need to be overcome. When looking at small-scale flow in rough fractures or at fractures edges, the same mechanism will play a role that will tend to restrict flow and develop non-linear, i.e. tortuous, flow. This behaviour, of course, exerts a strong influence when voids are being re-wetted by water or a more viscous fluid.

Where a fluid is percolating in an inclined fracture $(\beta)$, access to the adjacent fracture element can occur if the weight of the saturated fluid column in the fracture $(2 h)$ exceeds threshold capillary pressure of that fracture element, hence:

$$
\gamma h \sin \beta=2 T_{S} / e
$$


When capillarity is significant, flow would be by gradual percolation and pore invasion, depending upon the interaction of gravitational and capillary forces.

\section{$6 \quad$ Field scale conditions}

Fracture connectivity relationships indicate that often there are a relatively small number of fractures of high persistence or continuity within most rock masses but, instead, a larger number of shorter length fractures tends to connect to form a network. Connectivity within a field-scale network is a function of fracture aperture, fracture connectivity and fracture spacing or intensity.

\subsection{Aperture}

The sensitivity of fracture conductivity to aperture and fracture frequency is well illustrated in Figure 9, confirming that:

- One order of magnitude change in aperture size is equivalent to three orders of magnitude in hydraulic conductivity.

- One order of magnitude of change in joint spacing is theoretically equivalent to a change of one order of magnitude of hydraulic conductivity.

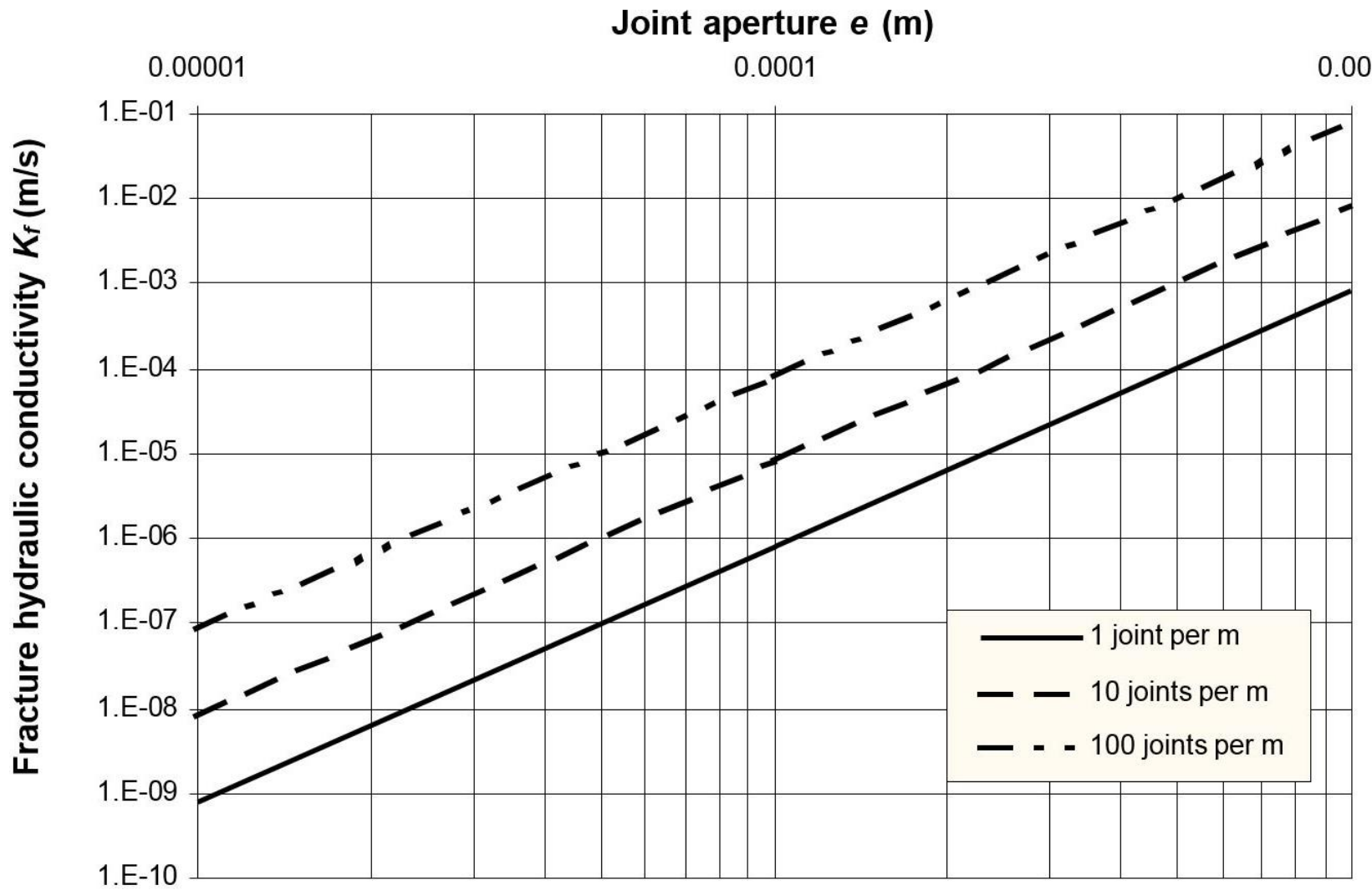

Figure 9 Influence of joint aperture $(e)$ and joint spacing on hydraulic conductivity $\left(K_{f}\right)$ in the direction of a set of smooth joints (after Hoek \& Bray 1981)

\subsection{Fracture continuity}

Fracture continuity or persistence is something that can only be effectively measured in outcrop, rather than in boreholes, and requires observation of a significant number of fractures to provide confidence that the upper limit of distribution, which is truncated in the outcrop, can be estimated. Continuity is often assumed by authors to have a log-normal or exponential distribution. The geological mode of formation or genus of the fracture often gives an indication of the expected continuity (Figure 10). 


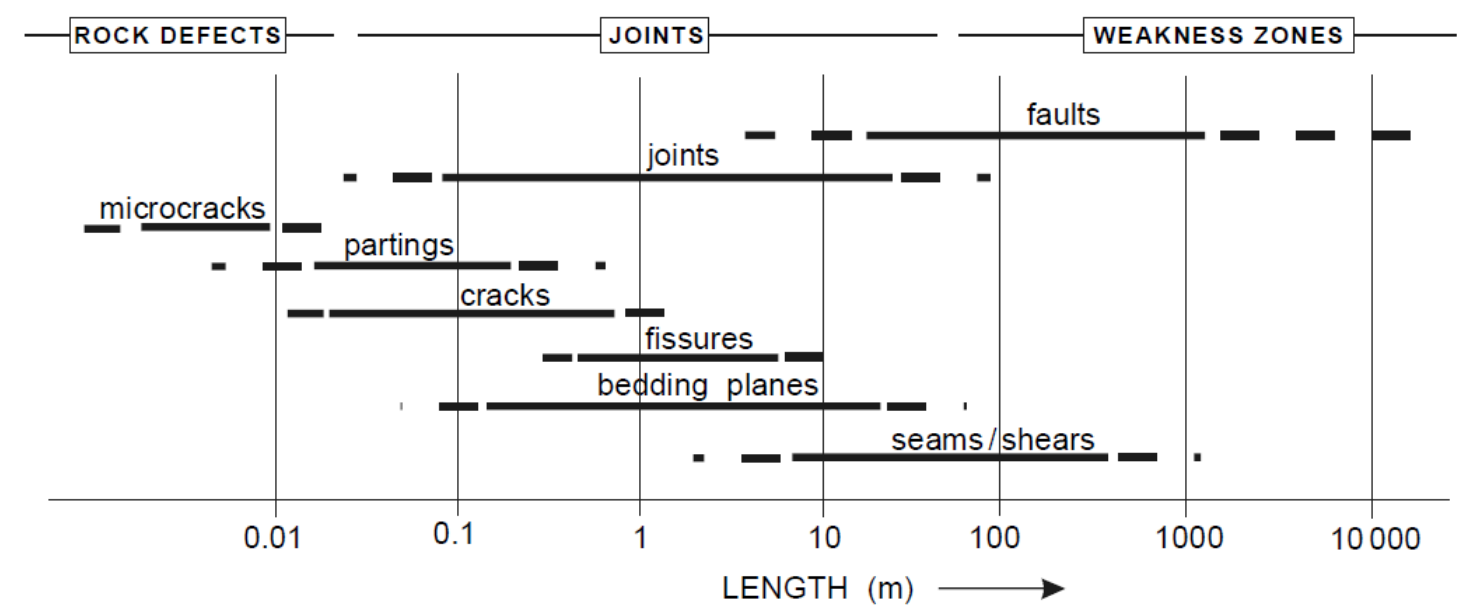

Figure 10 Fracture continuity classified by common geological structures (Palmström 2001)

In general terms, the most continuous structures are typically faults, with shears forming an intermediate grouping, and cracks or microcracks typically forming a less continuous set. Joints, bedding planes and foliation can occur within a range of intermediate to most continuous.

\subsection{Fracture spacing and intensity}

The quality of discontinuity spacing measurement data depends strongly on the rock mass conditions and sample line or plane orientation. Ideal conditions for spacing are in blocky rock masses with moderate relief, with structure dominated by a few approximately orthogonal discontinuity sets.

In massive rock mass with few fractures, or in conditions where fracturing is non-systematic or joint sets are unfavourably oriented with respect to bench face window maps, then spacing data may be difficult to collect, or highly randomised and dependent on sampling location (Figure 11). Measurements made in outcrops and boreholes are always subject to sources of bias and uncertainty that should be at least qualitatively accounted for.

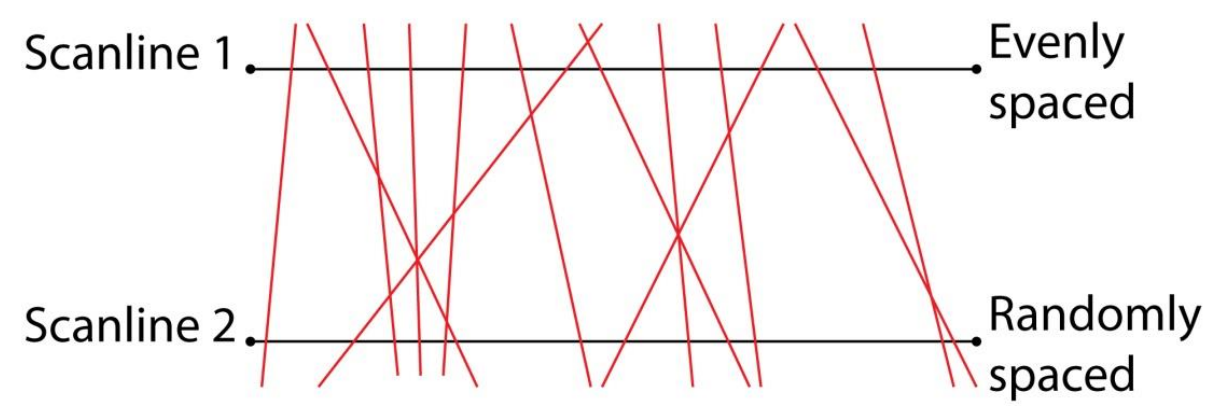

Figure 11 Randomness in spacing measurement (reproduced from Priest 1993)

Fracture intensity is a measure of fracture frequency used in the generation and validation of statistical discrete fracture network models (Dershowitz \& Herda 1992). Intensity can be expressed in terms of linear intensity $\left(\mathrm{P}_{10}\right)$ from borehole or scanline measurements, areal intensity $\left(\mathrm{P}_{21}\right)$ from areal information, e.g. window mapping data, or in terms of true volumetric intensity $\left(P_{32}\right)$, which expresses the total surface area of fractures in a unit volume of rock mass (Figure 12). 


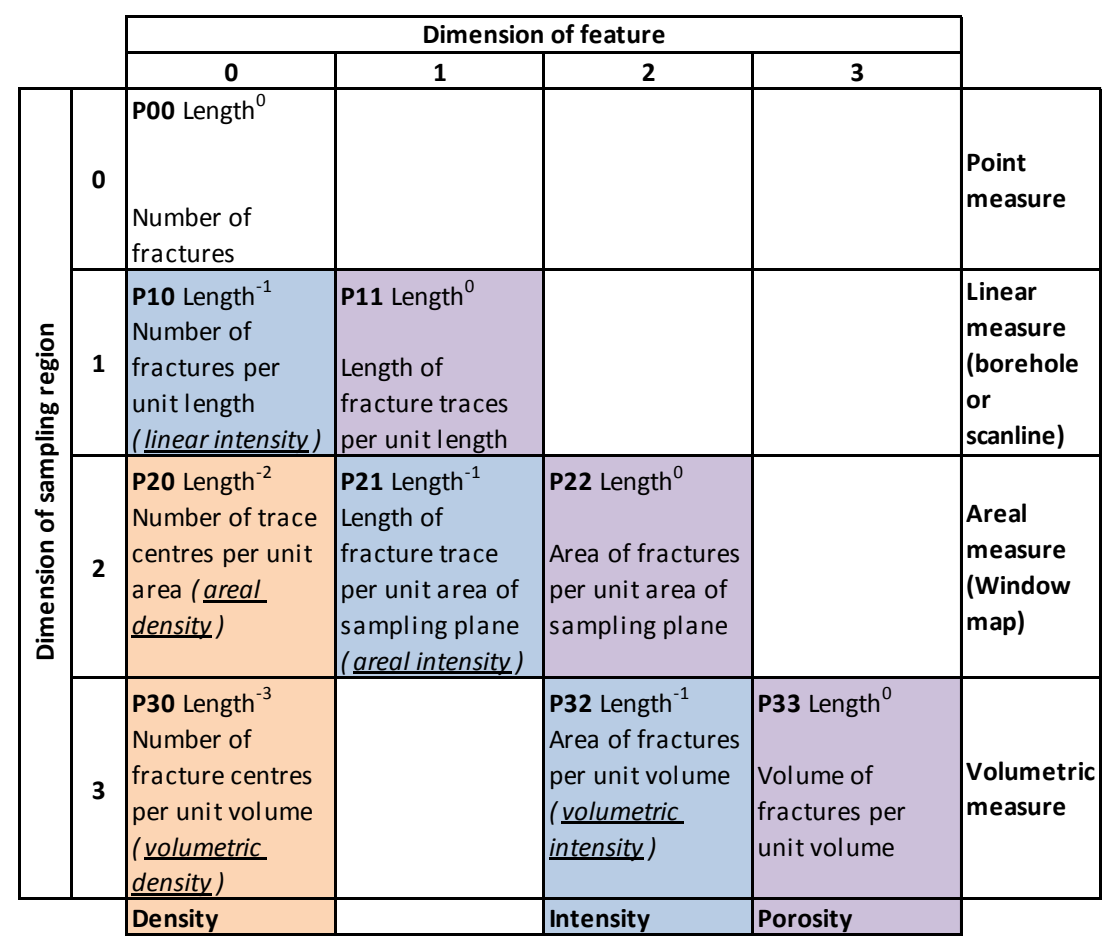

Figure $12 \mathrm{Pij}$ system of fracture frequency measurement for fracture network investigations

Figure 13 shows histograms of linear intensity $P_{10}$ derived from the in-window scanline mapping, along with a calculated overall discontinuity spacing derived from taking the inverse of the $P_{10}$ data for each digital window. The data compares well to log-normal and exponential distributions that we often see.

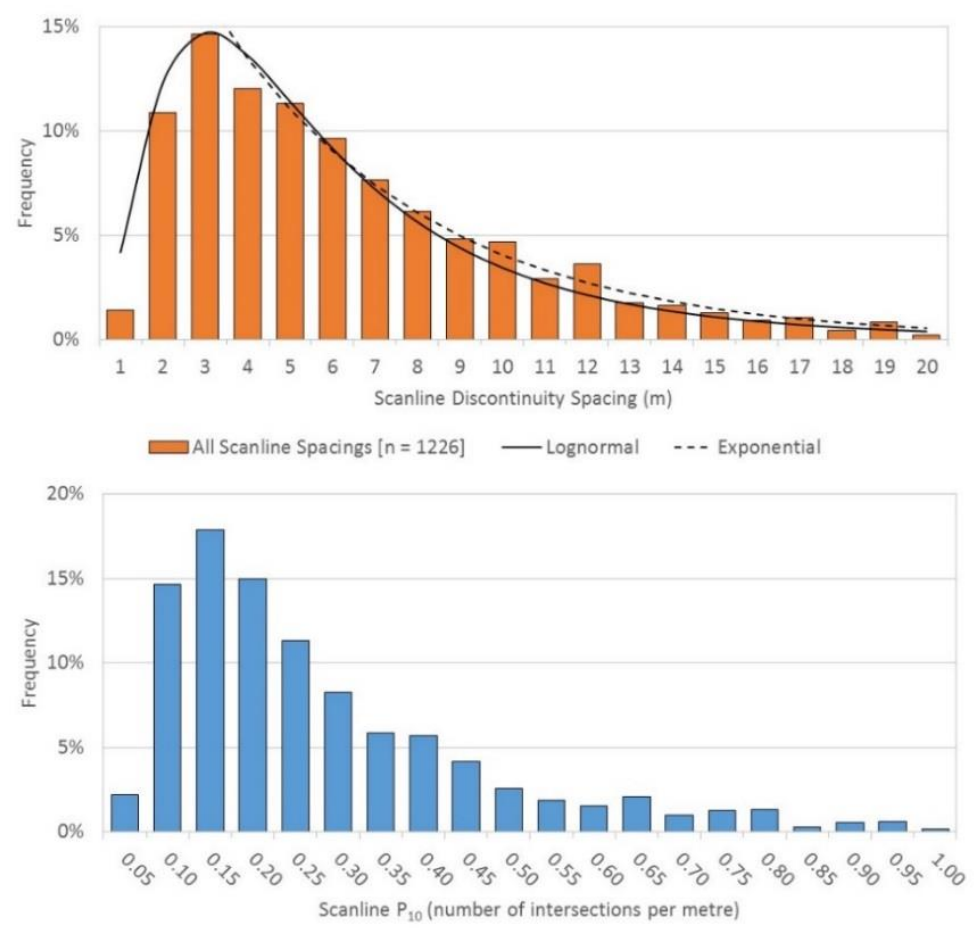

Figure 13 Overall distribution of scanline spacing measurements and calculated horizontal scanlines $\left(\mathrm{P}_{10}\right)$

This figure reinforces the importance of defect spacing on potential hydraulic behaviour of rock masses, although it is the interconnectedness of conducting fractures that is important from a perspective of groundwater control. The available porosity (intergranular or fracture controlled), $\mathrm{P}_{33}$, is the factor that is of greatest significance when considering groundwater and pore pressure control. 


\section{$7 \quad$ Pore pressure management}

The foregoing discussion has highlighted the sensitivity of flow to the driving hydraulic gradient in order to overcome the resisting capillary pressure that enables voids to be recharged and for seepage to occur. Aggressive mine schedules can endanger satisfactory slope performance if the vertical advance rate exceeds the capacity of the rock mass to drain or depressurise naturally. In these cases, slope depressurisation can often be created by the installation of lateral or (sub-) horizontal drains. These conditions are often most prevalent in weak, weathered or altered rocks, or where there are water bearing structures.

The need for, or effectiveness of, these measures is a function of the hydraulic conductivity of the rock mass, the strength of the rock mass and the location of the piezometric surface, which is often not clear when mining commences. Drain holes often present a flexible and efficient method to maintain a slope behaviour in accordance with the design criteria.

\subsection{Depressurisation sensitivity model}

For the next part of the paper, the 3D rock mass response to depressurisation is studied in terms of the effect of transient seepage on slope stability. The aim of the analysis is to demonstrate how simple repeatable forms of analysis can be used to allow rapid assessment of any slope stability implications related to the degree of depressurisation. The results can then be used to calibrate field trials or evaluate slope rehabilitation options. For this exercise, a 3D FEFLOW (WASY 2009) model was used to provide pore pressure output that has been analysed using accepted 2D limit equilibrium analyses (Rocscience 2002).

The analyses considered a $150 \mathrm{~m}$ high, $50^{\circ}$ slope and evaluated the transient pore pressure in a simple 3D model $200 \mathrm{~m}$ wide and made of a rock mass comprising a single hydraulic conductivity. The seepage model was created with a uniform and homogenous hydraulic conductivity, selected to represent the bulk conductivity of a weathered or altered rock mass, i.e. the effect of geological structure model implicitly as a continuum. The model was run for three conductivity cases to represent the common range of moderate to low permeability rock mass conditions: values of $1 \times 10^{-5}, 1 \times 10^{-7}$ and $1 \times 10^{-9} \mathrm{~ms}^{-1}$. The model is shown in Figure 14.
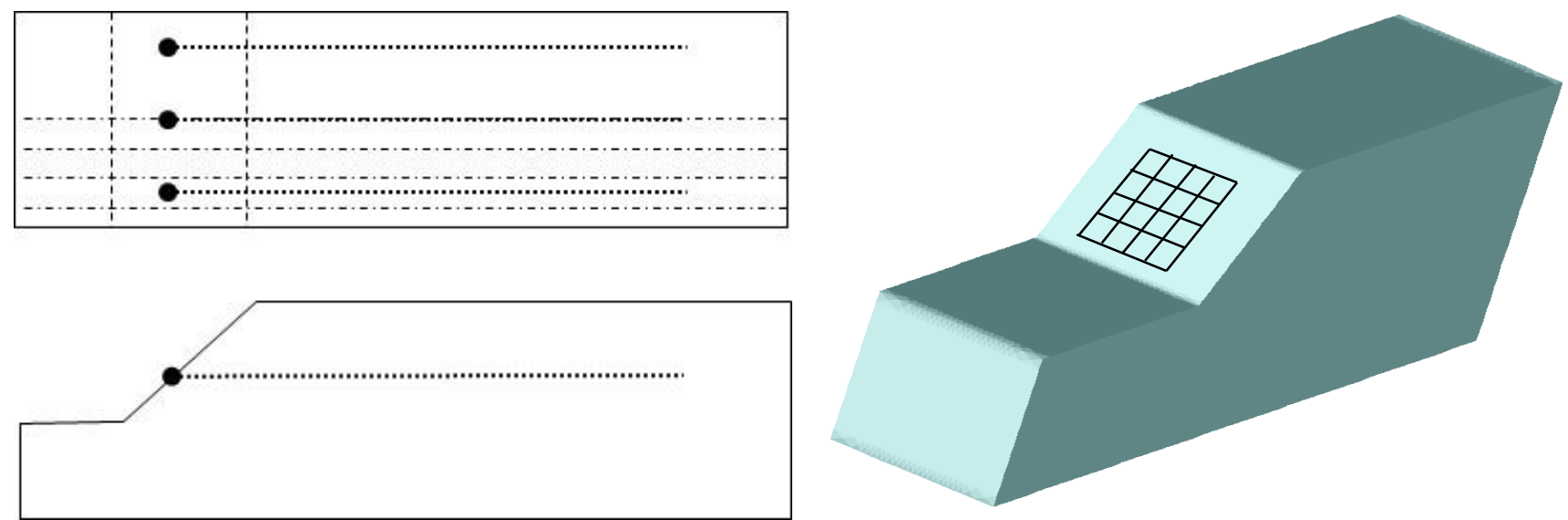

Figure 14 Conceptual depressurisation model in plan and section showing cross-section planes and with drain collar configuration in oblique view

Horizontal drains modelled as $100 \mathrm{~mm}$ diameter and $100 \mathrm{~m}$ long were positioned with the centres gridded at 25,50 and $100 \mathrm{~m}$ spacing, with rows either orthogonal or offset. The following are the spacing combinations used (vertical to lateral): 100 by $100 \mathrm{~m} ; 50$ by $50 \mathrm{~m} ; 25$ by $25 \mathrm{~m} ; 50$ by $25 \mathrm{~m}$; and 25 by $50 \mathrm{~m}$. The pore pressures developed at critical time steps were extracted as vertical slices and analysed using limit equilibrium stability models for an assumed set of material properties. The results gave a Factor of Safety (FS) for a slice at a particular time for a rock mass of a particular conductivity. 


\subsection{Results}

The pore pressure distribution within vertical planes through the model varies with the relative location of horizontal drains. The profiles for three such locations are shown in Figure 15: plots (a) to (c) show the change in FS with time for $K=1 \times 10^{-7} \mathrm{~m} / \mathrm{s}$ due to different drain spacing, with lateral offsets of $50,37.5$ and $25 \mathrm{~m}$ from the drain; plots (d) to (f) show the influence of permeability on depressurisation pattern at 365 days.

(a)

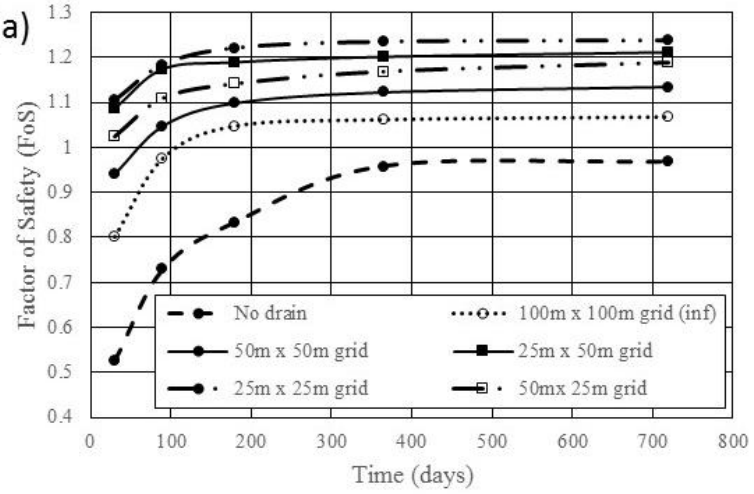

(b)

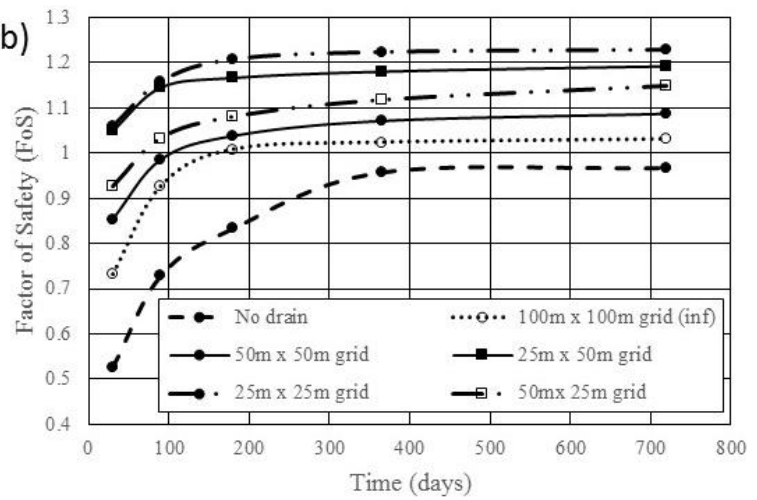

(c)

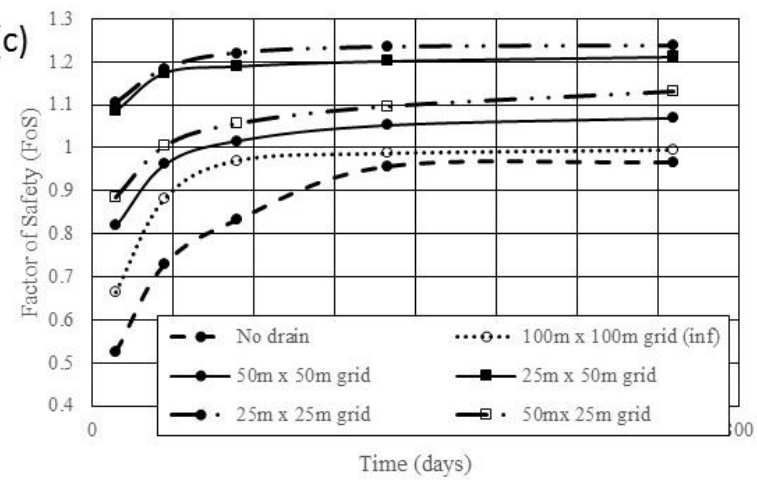

(d)

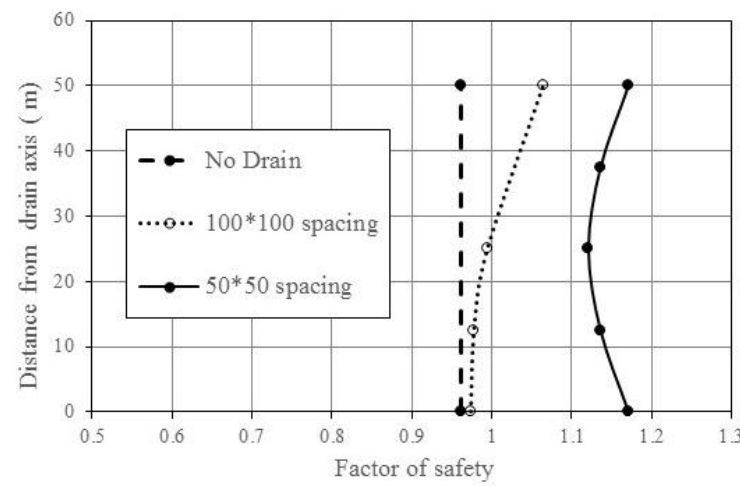

(e)

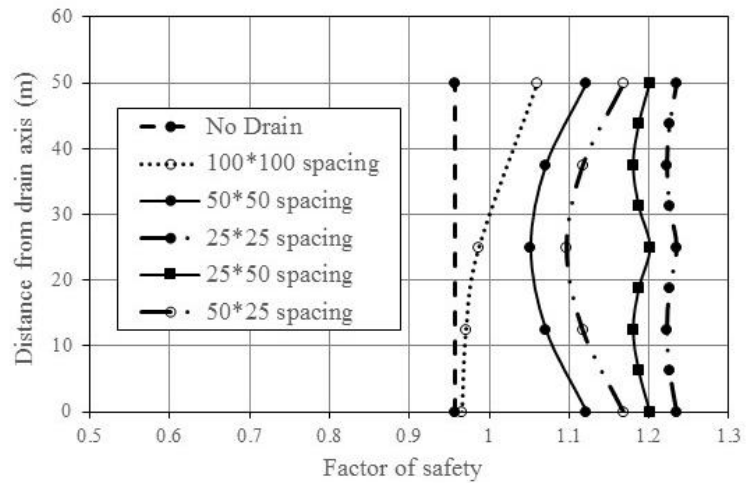

(f)

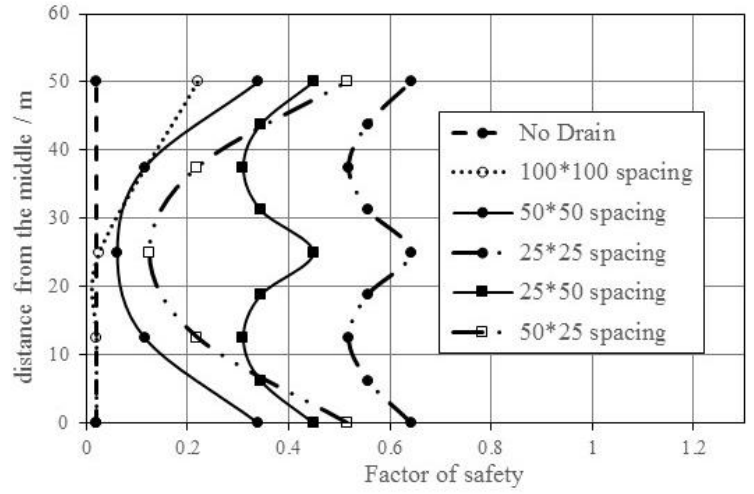

Figure 15 Change in Factor of Safety (FS) with time for offset slices $(5,7,9)$ at: (a) $50 \mathrm{~m}$; (b) $37.5 \mathrm{~m}$; (c) $25 \mathrm{~m}$ from the drain axis; and change in FS with offset from drain measured at 365 days for K of: (d) $1 \times 10^{-5}$; (e ) $1 \times 10^{-7}$; and, (f) $1 \times 10^{-9} \mathrm{~ms}^{-1}$

The FS results for $1 \times 10^{-7} \mathrm{~ms}^{-1}$, the mid-zone of the cases analysed, were picked as they are typical of the conditions encountered in many weathered rocks or saprolite (Figures 15(a) to 15(c)). The analyses show that where material strength is low, stable conditions ( $F S>1$ ) can take an impractically long time if, indeed, it can occur at all, unless assisted by depressurisation measures. The depressurisation effect has a disproportionate impact on stability over time (very high initial rate of change followed by a tailing off). 
For low to moderate permeability rocks and soils, the progressive reduction in the hydraulic gradient and the capillarity of the voids are the reasons for this observation. The fact that drainage or partial drainage has been achieved is important, since to re-wet the rock mass high hydraulic gradients will need to be reimposed, which may not be possible if the site surface water management measures are not well designed.

The depressurisation effect is also enhanced by increasing the intensity of drain spacing, although the results show that the positive impact of increasing intensity is more sensitive to reductions in the vertical spacing than laterally.

The lateral influence of depressurisation induced by drain holes is also interesting to observe. The maximum influence is achieved under the maximum hydraulic gradient; corresponding to the highest elevation of the piezometric surface, before drains were installed, and lowest head, typically atmospheric pressure at the interface of the drain and rock mass.

Considering the zone of influence that is expected to develop around a well, for a horizontal drain the same problem is seen but with the hydraulic gradient applied orthogonally, i.e. perpendicular to the axial plane of the drain rather than perpendicular to the well head. For granular media, the assumed zone of influence of a well is 3D parabolic surface. For a horizontal drain, this form becomes vertically compressed initially with a limited zone of desaturation forming above the drain, as the seepage is concentrated through the zone of highest hydraulic gradient. In time, the gradient will reduce as a function of time and material permeability until an equilibrium is reached between the gradient and the capillary constraints of the rockmass.

When the influence of permeability is considered for the same time step, further interesting behaviour is indicated (Figures 15(c) to 15(e)). In these figures, the graphs show effectively a horizontal slice through the model in the plane of the drains. For each plot a different conductivity value is considered, representing a transition of hydraulic performance from moderately well-draining to very poor-draining. Each data point represents the FS for that conductivity model at a 365 day time step measured laterally at an offset from the drain.

The critical points are:

- At high to moderately high conductivity values $\left(1 \times 10^{-5} \mathrm{~ms}^{-1}\right)$, more effective improvement in slice FS can be achieved with relatively coarse drain spacing, with the model showing that typical bench scale FS design criteria have been achieved with little intervention.

- At low conductivity values $\left(1 \times 10^{-7} \mathrm{~ms}^{-1}\right)$, only limited zones of the slope would achieve the same bench scale criteria and it would be expected that extensive slumping would occur. This poor behaviour could be mitigated by decreasing the drain hole spacing, although sensitivity to lateral and vertical spacing would provide an opportunity to optimise the time and cost of the program.

- At very low conductivity values $\left(1 \times 10^{-9} \mathrm{~ms}^{-1}\right)$, the model simply shows that significant time periods could be required to achieve the range of likely acceptable FS, although in this case the nature of the geological conditions compared to the model assumptions needs to be carefully checked, e.g. an extremely low primary permeability shale could contain secondary permeability controlled by foliation, which upon exposure to stress relief in a pit wall, could result in a significantly more permeable material than initially assumed; as well as anisotropy, compositional variability can also lead to preferential flow paths developing in materials that have responded differently to alteration or weathering; the rock mass strength may be strong enough that this failure mode is not a controlling factor.

\section{Conclusion}

The key focus of this paper has been to review the large-scale and accepted rules that govern the performance of rock masses containing water. Amongst the established theory, it is important to understand the role of small-scale characteristics on the larger scale behaviour; local variability should be anticipated and will not necessarily be aligned with expected large-scale or conventional assumptions. Geological media 
contains anisotropies, in terms of composition and joint fabrics, which will potentially alter the way that slopes behave.

Geotechnical problems usually impact in areas where the worst conditions or properties are encountered rather than at average or upper quartile intervals. For this reason, it is important to take steps to increase confidence in geotechnical data so that the geotechnical model can be optimised. This includes taking opportunities for ongoing data collection and testing design assumptions against actual field behaviour so that likelihood, variability, and area of influence, can be best anticipated or managed.

The analyses show that the rate of change of FS with time and depressurisation measures confirm that timely intervention results are the most effective control of problem behaviour, where groundwater is concerned. Pore pressure gradients developed around drain holes are essential for effective depressurisation and the degree that can be achieved is related to the permeability of the rock mass and the corresponding capillarity. Once depressurised or drained, good water management can make it very difficult to remobilise the materials under the same moisture conditions.

\section{Acknowledgement}

The author wishes to note the support and input of others across the stages of the presented work. The fundamental work is based upon research collaboration with Professor Buddhima Indraratna (University of Wollongong, Wollongong, New South Wales), and Dr Winton Gale (Strata Control Technology), and especially Professor Ranjith P Gammage (Monash University, Melbourne, Victoria). The theoretical work has been more recently assisted by Dr Jaya Mylvaganam and Zack Tuckey (SRK Consulting (Australasia) Pty Ltd, Australia) as well as other SRK Consulting colleagues in Australia and overseas, with opportunities, also, for client feedback, especially from Isaac Baidoo and Musah Abdulai (originally GoldFields Ghana).

\section{References}

Barton, N \& Bandis, S 1980, 'Some effects of scale on the shear strength of rock joints', International Journal of Rock Mechanics and Mining Sciences and Geomechanics Abstracts, vol. 17, pp. 69-73.

Barton, N \& Choubey, V 1977, 'The shear strength of rock joints in theory and practice', Rock Mechanics, vol. 10, pp. 1-54.

Barton, N, Bandis, S \& Bakhtar, K 1985, 'Strength deformation and conductivity coupling of rock joints', International Journal of Rock Mechanics and Mining Sciences and Geomechanics Abstracts, vol. 22, no. 3 pp. 121-140.

Beale, G, Price, M \& Waterhouse, J 2014, Framework: assessing water in slope stability, in G Beale \& J Read, Guidelines for Evaluating Water in Pit Slope Stability, CRC Press, Balkema, EH Leiden.

Brace, WF 1980, 'Permeability of crystalline and argillaceous rocks', International Journal of Rock Mechanics and Mining Sciences and Geomechanics Abstracts, vol. 17, pp. 241-251.

Brady, B \& Brown, ET 1994, Rock Mechanics for Underground Mining, 2nd edn, Chapman-Hall, London, p. 571.

Brown, SR 1987, 'Fluid flow through rock joints: the effect of surface roughness', Journal of Geophysical Research, vol. 92, no. B2, pp. 1337-1347.

Carlsson, A, Gustafson, G, Lindblom, U \& Olsson, T 1990, 'Scale effects in the determination of hydraulic properties of rock masses', in A Pinto da Cunha (ed.), Scale effects in rock masses, Balkema, Rotterdam, pp. 103-117.

Chen, DW, Zimmerman, RW \& Cook, NGW 1989, 'The effect of contact area on the permeability of fractures', in A Wahab Khair (ed.), Rock mechanics as a guide for efficient utilisation of natural resources, Balkema, Rotterdam, pp. 81-88.

Cook, AM, Myer, LR, Cook, NGW \& Doyle, FM 1990, 'The effect of tortuosity on flow through a natural fracture. Rock Mechanics Contributions and Challenges', in Proceedings of the 31st US Symposium on Rock Mechanics, Balkema, pp. 371-378.

Dershowitz, WS \& Herda, HH 1992, 'Interpretation of Fracture Spacing and Intensity', in Proceedings of the 33rd US Symposium on Rock Mechanics, Santa Fe, New Mexico.

Di Biagio, E 1973, Leakage of gas from underground storage facilities in rock, NGI report no. 97, pp. 15-30.

Elsworth, D \& Doe, TW 1986, 'Application of non-linear flow laws in determining rock fissure geometry from single borehole pumping tests', International Journal of Rock Mechanics and Mining Sciences and Geomechanics Abstracts, vol. 23, pp. 245-54.

Fredlund, DG \& Rahardjo, H 1993, Soil Mechanics for Unsaturated Soils, John Wiley \& Sons Inc, New York, p. 517.

Gale, J 1990, 'Hydraulic behaviour of rock joints', in N Barton \& O Stephansson (eds), Rock Joints, Balkema, Rotterdam, pp. 351-373.

Hakami, E \& Barton, N 1990, 'Aperture measurements and flow experiments using transport replicas', in N Barton \& O Stephansson (eds), Rock Joints, Balkema, Rotterdam, pp. 383-390.

Hoek, E \& Bray, JW 1981, Rock Slope Engineering Revised 3rd Edition, IMM London, p. 358.

Indraratna, B, Price, J \& Gale, W 2002b, 'Fourier Description of Fracture Roughness', in NARMS-TAC 2002, Mining \& Tunnelling Innovation \& Opportunity, University of Toronto, Toronto, pp. 35-44. 
Indraratna, B, Rambanda, P \& Singh, RN 1994, 'Numerical analysis of water inflows to underground excavations - current status and future trends', in 5th International Mine Water Congress, Nottingham, pp. 339-354.

Indraratna, B, Ranjith, PG \& Gale, W 1999a, 'Single phase water flow through rock fractures', Geotechnical and Geological Engineering, vol. 17, pp. 211-240.

Indraratna, B, Ranjith, PG \& Gale, W 1999b, 'Deformation and permeability characteristics with interconnected fractures', in 9th ISRM International Congress of Rock Mechanics, Paris, pp. 755-760.

Isherwood, D 1979, Geoscience Data Base Handbook for Modelling Nuclear Waste Repository, vol. 1 NUREG/CR-0912, UCRL-52719.

ISRM (International Society for Rock Mechanics) 1978, 'Suggested Methods for the Quantitative Description of Discontinuities in Rock Masses', in ET Brown (ed.), Part 1, Site Characterisation, Rock Characterisation Testing and Monitoring: ISRM Suggested Methods, Pergamon Press, Oxford.

Iwai, K 1976, 'Fundamental studies of fluid flow through a single fracture', PhD thesis, University of Berkeley.

Lee, CH \& Farmer, I 1993, Fluid Flow in Discontinuous Rocks, Chapman Hall, p. 169.

Lomize, GM 1951, 'Water flow through jointed rock', Gosenergoizdat, Moscow. [In Russian]

Long, JCS 1996, 'Rock Fractures and Fluid Flow: Contemporary understanding and applications', National Research Council Committee on Fracture Characterisation and Fluid Flow, National Academic Press, Washington, pp. 550.

Louis, C 1968, 'Etudes des écoulements d'eau dans les roches fissures et des leurs influences sure la stabilité des massifs rocheux', Bulletin De la Direction des Etud Et Rech. EDF, sér. A, 3, T2-F.

Louis, C 1969, 'A study of groundwater flow in jointed rock and its influence on the stability of rock masses', Rock Mechanics Research Report No. 10, Imperial College, London.

Louis, C \& Maini, YN 1970, 'Determination of in situ hydraulic parameters in jointed rock', in Proceedings of the 2nd Congress ISRM, pp. 1-32.

McMahon, BK 1985, 'Some practical considerations for the estimation of shear strength of joints and other discontinuities', in O Stephansson (ed.), Proceedings of the International Symposium on Fundamentals of Rock Joints, Centek, Luleå, pp. 475-485.

Makurat, A, Barton, N, Rad, NS \& Bandis, S 1990, 'Joint conductivity variation due to normal and shear deformation', in N Barton \& O Stephansson (eds), Proceedings of the International Symposium on Rock Joints, Rotterdam, Balkema, pp. 535-540.

Neuzil, CE 2003, 'Hydromechanical Coupling in Geologic Processes', Hydrogeology Journal, vol. 11, pp. 41-83.

Neuzil, CE \& Tracy, JV 1981, 'Flow through fractures', Water Resources Research, vol. 17, pp. 191-199.

Nichol, MJ \& Glass, RJ 1994, 'Wetting phase permeability in a partially saturated horizontal fracture', in Proceedings of the 5th Annual International High Level Radioactive Waste Management Conference, American Nuclear Society, pp. 2007-2019.

Patton, FD 1966, 'Multiple modes of shear failure in rock', in Proceedings of the 1st Congress of the International Society of Rock Mechanics, Lisbon, vol. 1, pp. 509-513.

Palmström, A 2001, 'Measurement and Characterization of Rock Mass Jointing', in VM Sharma \& KR Saxena (eds), In-Situ characterization of rocks, Balkema Publishers, Oslo, pp. 49-97.

Price, JR 2005, 'Coupled analysis of two-phase flow in rough rock fractures', PhD thesis, Department of Civil Engineering, University of Wollongong.

Priest, SD 1993, Discontinuity Analysis for Rock Engineering, Chapman Hall, London, p. 473.

Priest, SD \& Hudson, JA 1981, 'Estimation of discontinuity spacing and trace length using scanline surveys', International Journal of Rock Mechanics and Mining Sciences and Geomechanics Abstracts, vol. 18, pp. 183-197.

Pruess, K \& Tsang, YW 1990, 'On two-phase relative permeability and capillary pressure of rough walled rock fractures', Water Resources Research, vol. 26, no. 9, pp. 1915-1926.

Rocscience 2002, SLIDE ${ }^{\odot}$ Version 5.0 Users Manual, Rocscience Inc., Toronto.

Rutqvist, J \& Stephansson, O 2003, 'The Role of Hydromechanical Coupling in Fractured Rock Engineering', Hydrogeology Journal, vol. 11, pp. 7-40.

Stacey, P \& Read, J (eds) 2009, Guidelines for Open Pit Slope Design, CSIRO Publishing, Australia.

Sullivan, TD 1993, 'Understanding Pit Slope Movements', in T Szwedzicki (ed.), Geotechnical Instrumentation and Monitoring in Open Pit and Underground Mining, Balkema, Rotterdam.

Sullivan, TD 2007, 'Hydromechanical Coupling and Pit Slope Movements', in Y Potvin (ed.), Proceedings of the 2007 International Symposium on Rock Slope Stability in Open Pit Mining and Civil Engineering, Australian Centre for Geomechanics, Perth, pp. 3-44.

Terzaghi, K 1923, 'Die Berechnung der Durchlässigkeitziffer des Tones aus dem Verlauf der hydrodynamischen Spannungserscheinungen', Akad. Wissensch. Wien Sitzungsber. Mathnaturwissensch Klasse Ila, vol. 142 (3/4), pp. 125-138.

Tsang, YW 1984, 'The effect of tortuosity on fluid flow through a single fracture', Water Resources Research, vol. 20, pp. 1209-1215. Wang, HF 2000, Theory of Linear Poroelasticity, Princeton University Press, p. 287.

WASY 2009, FEFLOW ${ }^{\circledR}$ Finite Element Subsurface Flow and Transport Simulation System - Users Manual, WASY GmbH, Berlin.

Witherspoon, PA, Wang, JSY, Iwai, K \& Gale, J 1980, 'Validity of cubic law for fluid flow in a deformable rock fracture', Water Resources Research, vol. 16, no. 6, pp. 1016-1024.

Ziegler, TW 1976, Determination of Rock Mass Permeability: Final Report, Technical Report S-76-2, US Army Corps Engineers, Waterway Experiment Station, Vicksburg.

Zimmerman, RW \& Bodvarsson, GS 1996, 'Hydraulic conductivity of rock fractures', Transport in Porous Media, vol. 23, pp 1-30. 